\title{
IDO and Kynurenine Metabolites in Peripheral and CNS Disorders
}

\author{
Yi-Shu Huang, Joy Ogbechi, Felix I. Clanchy, Richard O. Williams and Trevor W. Stone* \\ The Kennedy Institute of Rheumatology, NDORMS, University of Oxford, Oxford, United Kingdom
}

The importance of the kynurenine pathway in normal immune system function has led to an appreciation of its possible contribution to autoimmune disorders such as rheumatoid arthritis. Indoleamine-2,3-dioxygenase (IDO) activity exerts a protective function, limiting the severity of experimental arthritis, whereas deletion or inhibition exacerbates the symptoms. Other chronic disorder with an inflammatory component, such as atherosclerosis, are also suppressed by IDO activity. It is suggested that this overall anti-inflammatory activity is mediated by a change in the relative production or activity of Th17 and regulatory $\mathrm{T}$ cell populations. Kynurenines may play an anti-inflammatory role also in CNS disorders such as Huntington's disease, Alzheimer's disease and multiple sclerosis, in which signs of inflammation and neurodegeneration are involved. The possibility is discussed that in Huntington's disease kynurenines interact with other anti-inflammatory molecules such as Human Lymphocyte Antigen-G

OPEN ACCESS

Edited by:

Elisa Wirthgen,

University Hospital Rostock, Germany

Reviewed by:

Johanna M. Gostner,

Innsbruck Medical University, Austria Katharina Hüfner,

Innsbruck Medical University, Austria

${ }^{*}$ Correspondence: Trevor W. Stone trevor.stone@kennedy.ox.ac.uk

Specialty section: This article was submitted to Inflammation, a section of the journal

Frontiers in Immunology

Received: 27 August 2019 Accepted: 18 February 2020

Published: 05 March 2020

Citation:

Huang Y-S, Ogbechi J, Clanchy Fl, Williams RO and Stone TW (2020) IDO and Kynurenine Metabolites in Peripheral and CNS Disorders.

Front. Immunol. 11:388.

doi: 10.3389/fimmu.2020.00388 which may be relevant in other disorders. Kynurenine involvement may account for the protection afforded to animals with cerebral malaria and trypanosomiasis when they are treated with an inhibitor of kynurenine-3-monoxygenase (KMO). There is some evidence that changes in IL-10 may contribute to this protection and the relationship between kynurenines and IL-10 in arthritis and other inflammatory conditions should be explored. In addition, metabolites of kynurenine downstream of $\mathrm{KMO}$, such as anthranilic acid and 3-hydroxy-anthranilic acid can influence inflammation, and the ratio of these compounds is a valuable biomarker of inflammatory status although the underlying molecular mechanisms of the changes require clarification. Hence it is essential that more effort be expended to identify their sites of action as potential targets for drug development. Finally, we discuss increasing awareness of the epigenetic regulation of IDO, for example by DNA methylation, a phenomenon which may explain differences between individuals in their susceptibility to arthritis and other inflammatory disorders.

Keywords: kynurenine, arthritis, lymphocyte antigens, 3-hydroxyanthranilic acid, Huntington's disease, T-cells

\section{INTRODUCTION}

Widespread interest in the kynurenine pathway (Figure 1) and its roles in the nervous and immune systems developed in parallel from the discoveries of indoleamine-2,3-dioxygenase (IDO) activation by interferon- $\gamma(1)$ and the subsequent discovery of a major functional role in placental immunity $(2,3)$ and the observation that catabolites of the IDO product, kynurenine, had modulatory effects on neuronal function (4-6) (Figure 2). It is now recognized that similar mechanisms may be involved at the molecular level of neuronal and non-neuronal processes 
and that activity along the kynurenine pathway is fundamental to the development of some central and peripheral disorders. Examples of these will be presented in this review, with the initial emphasis on disorders of primarily peripheral origin, including arthritis and atherosclerosis. A later section will emphasize the important links between peripheral and central inflammation by noting the roles of kynurenines and immune function in Alzheimer's disease, multiple sclerosis and Huntington's disease, where a relationship has been described between IDO and Human Lymphocyte Antigen-G. Those interactions may contribute to the roles of immune system activity in physiology and disease pathogenesis, with potentially common targets of therapeutic intervention for central and peripheral disorders.

\section{KYNURENINES AND PERIPHERAL INFLAMMATORY DISORDERS}

\section{Rheumatoid Arthritis}

The interface between tissue and immune system cells is seen clearly in peripheral inflammatory disorders such as rheumatoid arthritis (RA). In this condition, local tissue trauma and degeneration are accompanied by leukocyte infiltration and pannus formation which diminishes the volume of the joint space. This cellular infiltration and cytokine production eventually results in tissue damage and a positive feedback cycle in which the joint damage exacerbates the inflammatory response which in turn produces further bone and joint erosion.

Much work on the kynurenine metabolites in this condition has centered on the first enzymes of the pathway (IDO and tryptophan-2,3-dioxygenase, TDO), the isoforms of which have been discussed in depth (7). Where the identity of an isoform is known, it will be indicated in this review. The indeterminate form "IDO" implies that no distinction was made in the original literature. In general TDO, found mainly in the liver, exhibits greater selectivity for tryptophan whereas IDO, which occurs or can be induced in several tissues, acts on a wider range of indole-based substrates. As the enzyme most highly activated by interferon- $\gamma$ (IFN- $\gamma)$, IDO has often been the primary target used to explore disease mechanisms. In the case of RA, we have demonstrated that the inhibition of IDO (by 1-methylDL-tryptophan) or deletion of IDO1 increased the severity of arthritic symptoms in the collagen-induced model of arthritis (CIA) (8). The symptoms were, however, reduced significantly by the administration of kynurenine indicating that it was probably the loss of kynurenine or its downstream catabolites which were responsible for enhancing the arthritic symptoms and histopathology. Importantly, the effects of IDO inhibition included an increase in the numbers of IFN- $\gamma$ - and interleukin17- (IL-17)- producing T lymphocytes, particularly in the joints (8), suggesting a normally restraining influence of IDO. This is entirely consistent with the concept that RA is characterized by pathogenic T cells, including Th1 and Th17 cells.

In order to assess whether these observations might be relevant to RA in human patients, we considered mechanisms by which IDO or its activation processes might be affected in human subjects. One important mechanism for the regulation of IDO1 results from interaction between the B7 complex on dendritic cells (DCs) with Cytotoxic T-lymphocyte Antigen-4 (CTLA-4) expressed in the membranes of regulatory $\mathrm{T}$ cells. This ligation induces and activates IDO1 in the DCs and is maintained by Transforming Growth Factor- $\beta$ (TGF- $\beta$ ) and inflammatory mediators via non-canonical actions of Nuclear Factor $-\kappa \mathrm{B}(\mathrm{NF} \kappa \mathrm{B})$. This route is one of the major processes by which immune tolerance is maintained in a stable, long-term manner (9) and is an important link between arthritic damage and the kynurenine pathway. Subsequently we were able to demonstrate that in patients with RA there was a defect of IDO1 induction in the immune system involving the B7 / CTLA-4 interaction. The mechanism of this defect proved to be aberrant DNA methylation at the CTLA-4 promoter, leading to a loss of Treg cells and increased symptoms in the patients (10). The genetically impaired IDO1 activation thus reproduced the effect of arthritis exacerbation in IDO1-/- mice. The full cycle of events which explains the development, progression and remission of RA remains to be defined, but it is clear that IDO in DCs plays a significant role in that cycle. Since the simple procedure of administering kynurenine can reduce the degree of tissue damage and disability (8), this might represent a potential avenue for novel treatments.

It is perhaps unfortunate that IDO is such a clear and easily reproducible feature of inflammation since many studies have focussed almost exclusively on this enzyme and have interpreted the findings in terms of the full kynurenine pathway. The ratio of kynurenine to tryptophan concentrations in the blood or tissues has become a widely accepted marker of immune system activation, without a full appreciation of changes in the levels and relative amounts of metabolites downstream of kynurenine3-mono-oxygenase (KMO). It is now clear that the effects of IDO activation are mediated not only via the reduced availability of tryptophan, but also by those downstream metabolites. These compounds have direct effects on the immune system that regulate the initiation, progression and termination of immune responses to infection or tissue damage.

Examples of these effects include the ability of kynurenine or kynurenic acid to activate the Aryl Hydrocarbon Receptor (AHR) which in turn induces an increased expression of IDO and TDO, providing a positive feedback circuit (11-14). The progressively increasing levels of kynurenine have two critical actions: induction of the transcription factor Forkhead BoxP3 (FoxP3) (15-17) and suppression of the transcription factor Retinoic Acid Receptor-related Orphan Receptor- $\gamma \mathrm{t}$ (ROR $\gamma \mathrm{t})$ $(18,19)$. FoxP3 promotes the differentiation of CD4+ T cells to $\mathrm{CD} 4+\mathrm{CD} 25+\mathrm{FoxP} 3+$ regulatory $\mathrm{T}$ helper cells (Tregs) which are able to inhibit other CD4+ cells and the cytotoxic effector $\mathrm{T}$ cells such as CD8+ T cells and Natural Killer (NK) cells. The inhibition of ROR $\gamma \mathrm{t}$ expression prevents the differentiation of CD4+ T cells into generally pro-inflammatory Th17 cells. Since the work described above had indicated a role for Th17 and Treg cells in CIA, involvement of the AHR and its feed-forward generation of IDO/TDO might be relevant.

Activation of AHRs by their classic agonist hydrocarbon molecules such as benzo[a]pyrene and 2, 3, 7, 8tetrachlorodibenzo-p-dioxin (TCDD) could potentially account 

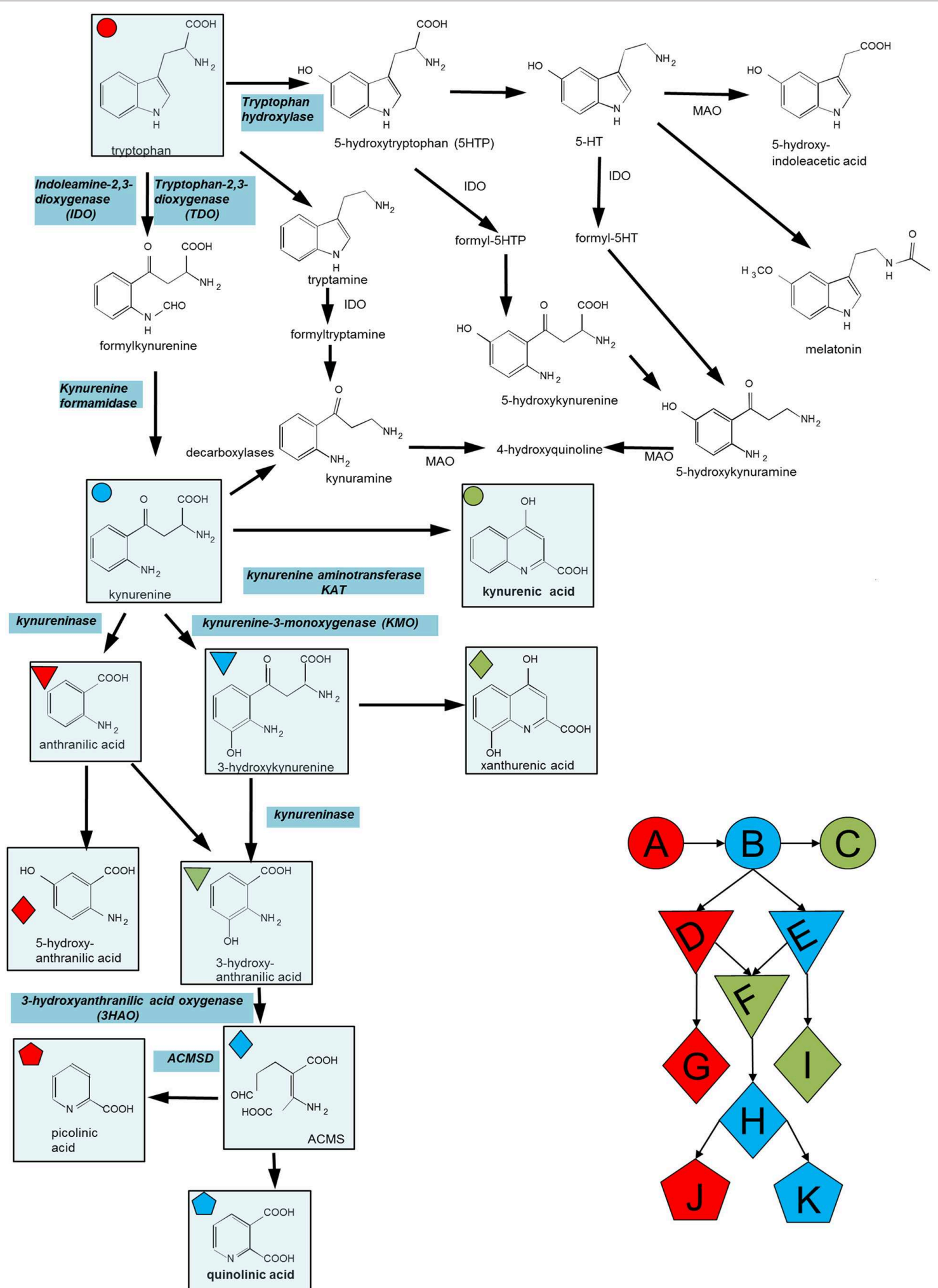

FIGURE 1 | Summary of the major compounds and enzymes of the kynurenine pathway. ACMSD is $\alpha$-amino- $\beta$-carboxymuconate semialdehyde decarboxylase. In cells lacking this enzyme the molecule in parentheses (ACMS) rearranges spontaneously (non-enzymatically) to quinolinic acid. When present, ACMSD converts ACMS to picolinic acid. Key metabolites include (A) Tryptophan, (B) Kynurenine, (C) Kynurenic acid, (D) Anthranilic acid, (E) 3-hydroxy-kynurenine, (F) 3-hydroxy-anthranilic acid, (G) 5-hydroxy-anthranilic acid, (H) ACMS, (I) xanthurenic acid, (J) picolinic acid, and (K) quinolinic acid. 

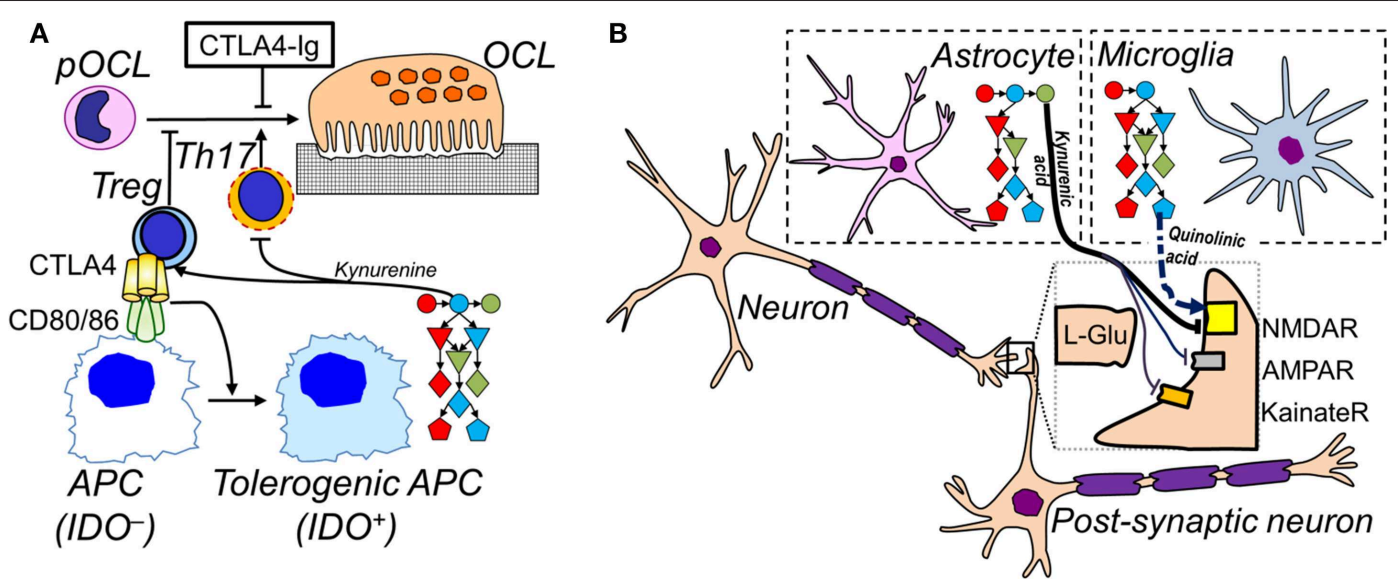

FIGURE 2 | Cell-specific IDO pathways in inflammation. (A) In the immune system, APCs upregulate expression of the complete IDO pathway when activated. Tolerogenic APCs promote the differentiation of Tregs and inhibit Th17 differentiation. Tregs inhibit APC activation via CTLA-4, which also inhibits differentiation of pre-osteoclasts (pOCL) to osteoclasts (OCL); soluble CTLA4-Ig (ipilimumab) also inhibits OCL differentiation. Conversely, Th17 promote osteoclastogenesis. (B) In the CNS, microglia express low levels of kynurenine aminotransferase, pushing the IDO pathway to the production of excitatory and potentially neurotoxic quinolinic acid (dashed arrow). Astrocytes express low levels of KMO which leads to the accumulation of the NMDA receptor blocker and neuroprotective kynurenic acid (full arrows). See Figure 1 for legend to IDO pathway metabolites.

for the exacerbation of RA in cigarette smokers (20-22). Indeed, activation of AHRs by the constituents of cigarette smoke can potentiate the induction of NFkB by Tumor Necrosis Factor- $\alpha$ (TNF- $\alpha$ ), leading not only to increased inflammatory activity but also reducing the efficacy of anti-TNF- $\alpha$ medications and possibly explaining both the apparent resistance of some patients to these drugs but also the high rate of non-compliance or discontinuation (23). The mechanism of AHR in these cases is likely to involve changes in the number and activity of Th17 cells (21) consistent with the evidence noted above. The exacerbation of symptoms in models of arthritis such as CIA and antigen-induced arthritis (AIA) is prevented by deletion of either AHRs or of IL-17 receptors (21) supporting the view that AHR activation can drive Th17 differentiation.

Helping to understand the mechanisms underlying RA, osteoarthritis (OA) and osteoporosis (OP) is the finding that the effects of AHR activation are potentiated by Human Leucocyte Antigen-DRB1, a significant risk factor for the development of arthritis (24). The synergism is sufficient to increase osteoclast generation and thus bone damage but, even more relevant systemically, the combination increases Th17 cell differentiation with high IL-17 levels noted in arthritic joints and draining lymph nodes.

Conversely the activation of AHRs by compounds with known anti-arthritic potential, such as sinomenine and norisoboldine, promote the differentiation of Treg cells $(25,26)$. Since the AHR is known to respond differentially to various compounds and to produce effects that depend qualitatively on the agonist, it will be of interest to determine whether these effects reflect a known or novel target site on the AHR complex which might be amenable to new drug development. An unrelated compound, tetrandrine, combines both these actions and normalizes the Th17: Treg ratio by a mechanism which involved the AHR (27). However, it is unclear whether the compound acts on two distinct target sites on the AHR, or whether the result of acting at a single site drives two different responses in Th17/Treg precursor cells. It is possible, for example, that tetrandrine has different sites of action in the two populations or that it induces different responses when acting on AHRs in cells destined to become Th17 and Treg precursors. These uncertainties would be important matters to clarify as they could lead to more selective molecules with a single mechanism of action which might be devoid of unwanted effects on other cell populations.

In addition to these promoters of AHR activity, several routes are now known by which AHR activity can be down-regulated. The microRNA molecule miR-223 for example suppresses AHR activity by interfering with the AHR Nuclear Translocator (ARNT) (28). Of particular interest was the observation that this interaction occurred in macrophages, but was less prominent in patients with RA than those with osteoarthritis, supporting proposals that these cells play an important role in the etiology of RA. However, these results are difficult to reconcile with the report that AHR deletion from thymocytes reduced arthritic parameters in mice with CIA, whereas deletion selectively from macrophages had no effect (13).

Since AHR expression is seen in most cell types, it is important to consider that immune system cells may be the dominant population involved in the regulation of arthritic inflammation. Nevertheless, it has been reported that the fibroblast-like synovial cells, which exhibit a high rate of proliferation and migration within the joints of patients with RA, also express AHRs. Activation of the receptors comprehensively inhibits the synovial cells, reducing proliferation, migration and invasion of surrounding tissue (29). A role for IDO in these phenomena has not been studied in depth but would be predicted as a significant feature of AHR activation elsewhere. 
Although there is continuing controversy about the relative importance of tryptophan depletion and kynurenine metabolite activity in immune system regulation $(30,31)$, it is likely that both mechanisms are relevant to some extent. While kynurenine and its metabolites are the primary biologically active compounds in the kynurenine pathway, the changes of their concentrations in blood or CSF are often small, as is the reduction in tryptophan concentration resulting from its oxidation (to kynurenine) by IDO or TDO. Much of the behavioral work in experimental animals, or clinical work in humans, includes the measurement of the kynurenine: tryptophan $(\mathrm{K} / \mathrm{T})$ ratio, which provides a larger and statistically more useful parameter. The effects of tryptophan depletion are likely to be mediated by activation of the Generalized Controller Non-derepressible-2 Kinase (GCN2) $(16,32,33)$, a sensor of cellular amino acid levels. A reduction in the concentration of tryptophan, for example, results in increased numbers of free tryptophanyl-tRNA molecules which induce GCN2 activation. Cells expressing IDO, such as plasmacytoid DCs, therefore, can induce T cell anergy by reduced proliferation and induced apoptosis $(32,34)$. Although GCN2 is usually considered to be necessary for linking tryptophan deficiency to the inhibition of cell cycling, it is possible that this relationship operates differently in CD4+ and CD8 + T cells (35). The effect of tryptophan depletion is potentiated by tryptophan catabolites in the kynurenine pathway (16).

\section{Osteoporosis}

Osteoporosis is another musculo-skeletal disorder in which inflammation is thought to play a significant role although the involvement of kynurenines remains poorly understood. When quantifying the levels of kynurenines in patients newly diagnosed with osteoporosis (and therefore receiving no relevant medication at the time), it was found that the serum content of 3-hydroxy-anthranilic acid (3HAA) was substantially lower (around 10-fold) than that in a parallel cohort of normal control subjects. Moreover, there was a comparably increased concentration of anthranilic acid (AA), generating an overall difference in concentration between these compounds of approximately 100:1. After treatment with the standard drugs - bisphosphonates or Selective Estrogen Receptor Modulators (SERMs) for 2 years, these values had returned to the levels determined in control subjects, accompanied by a significant improvement in measurements of bone density (36).

Both the mechanism and the pathological significance of this remain unclear. There have been suggestions of enzymic conversion of AA to 3HAA (37) which, potentially, might be inhibited during the course of inflammation resulting in a higher AA: 3HAA ratio. It is not known, however, whether these changes in the kynurenine pathway are primary or secondary contributory factors in the development of osteoporosis. 3HAA exerts inhibitory control of Th1 cells, changing the important ratio between inflammatory, IFN- $\gamma$-secreting Th1 cells and antiinflammatory IL-10 secreting Th2 cells with a resulting antiinflammatory polarization of immune system function (38). A loss of 3HAA should therefore result in a pro-inflammatory environment and could account for the emergence of a disorder such as osteoporosis in which the immune system is likely to be involved (39-41).

But what could generate the loss of 3HAA? Could it simply be a defective enzyme converting anthranilate to AA to 3HAA? Or might there be a reduced oxidation by KMO of kynurenine to 3-hydroxy-kynurenine (3HK), with kynureninase catabolising the excess kynurenine to AA? Why then is there no comparable increase in the conversion of kynurenine to kynurenic acid via kynurenine aminotransferase (KAT)? Do therapeutic agents affect the kynurenine pathway directly, in which case those effects might drive the AA:3HAA ratio and determine the initiation and time course of inflammation, or are all the kynurenine pathway changes a result of altered levels of a crucial factor such as a regulatory cytokine, chemokine or growth factor? Certainly 3HAA is less stable than AA in aqueous media, as discussed previously (42), largely because it is a reactive compound which auto-oxidizes to a form which dimerises spontaneously to cinnabarinic acid $(43,44)$. However, this molecular difference does not readily account for the differences in concentrations observed between two populations of patients, since the chemical and redox environment should not differ greatly between the groups.

The importance of these questions lies not simply in an understanding of osteoporosis, but also in accounting for similar changes in a wide range of disorders in which an underlying inflammation appears to be involved. Thus, similar, though not as dramatic, changes in AA: 3HAA ratio have been reported in a range of disorders [see $(30,31,42)$ ] where they can change progressively with the development of disease symptoms (45).

In attempting to explain some of these phenomena, several groups have turned to vitamins and the possible relevance of a deficiency in their availability. One plausible view is that disturbances to the kynurenine pathway may result from a deficiency of pyridoxal phosphate, one form of vitamin B6 which is a crucial co-factor for several kynurenine pathway enzymes such as kynureninase and kynurenine aminotransferase. Although not previously considered, riboflavin (vitamin B2) is also required, along with pyridoxal phosphate, for the activation of $\operatorname{KMO}(46,47)$. Infections and inflammation are associated with increased turnover of this cofactor (48), lowering cytosolic concentrations, a relationship consistent with the ability of riboflavin to inhibit the production of inflammatory cytokines (49), to potentiate the effects of anti-inflammatory drugs $(49,50)$ and to enhance host resistance $(51,52)$. Conversely, reduced riboflavin availability is associated with greater inflammatory activity in arthritis (53). Thus, the lowering of riboflavin content associated with the onset of inflammation, in turn producing suppressed KMO activity and the preferential metabolism of kynurenine to AA, could account for the high AA: 3HAA ratio observed in osteoporosis (36). As noted above, a similar elevation in this ratio has been reported in patients with arthritis (54) and other chronic disorders involving tissue inflammation (42).

As in RA, the AHRs seem to play a significant role in the regulation of bone turnover and fragility. Activation of AHRs enhances osteoblast production with corresponding increases in bone formation and strength (55). Similarly, Michalowska et al. (56) reported that kynurenine promotes osteoblast formation, 
possibly resulting from its inhibition of myeloid mesenchymal stem cell proliferation and the consequent loss of osteoblast precursors. On the other hand, there is evidence that the renal deficiency which results from kidney damage or loss increases the expression of AHRs in osteocytes and elevates plasma levels of a range of metabolites including kynurenine and 3hydroxykynurenine (3HK) (57). These changes are associated with increased numbers of osteoclasts, with kynurenine levels inversely related to several parameters of bone formation. Overall it was suggested that the AHR-mediated production of kynurenines mediated the osteoclast generation. In addition, while AHR generation of kynurenines promotes bone formation, the activation by AHR of the Cytochrome P450 enzymes promotes osteoclast activity so reducing osteogenesis, whereas AHR deletion was reported to increase bone development and density (58). It is clearly important not only to establish the reasons for the differing conclusions on kynurenine activity but also whether the various effects of AHR activation are mediated by kynurenine metabolites, cytochrome enzymes or other routes, and how those different routes interact with each other and with overall tissue function.

Also introducing an element of confusion is evidence that the presence of inflammation may alter the actions of AHRs. Thus, increased expression of AHRs was demonstrated in mesenchymal stem cells from mice with CIA (59) and this was associated with reduced production of osteoblasts. Treating the animals with AHR agonists further reduced bone formation, potentially representing a contributory mechanism in osteoporosis (55). Clearly it is essential to know whether the behavior of cells and receptors differs significantly between a normal physiological state and that of the pathological, diseased state since it would impact on the approach needed for therapeutic developments.

These various factors may also be complicated by dietary considerations. Increasing attention is being devoted to dietary regulation of metabolism, with directly acting AHR agonists such as $3,3^{\prime}$-diindolylmethane being of special interest. This and related compounds occur in several Brassica species of vegetables and have been found to inhibit osteoclast numbers and activity, resulting in enhanced bone formation (60). Again, it will be valuable to establish whether the kynurenine pathway is involved in this, and how it interacts with, and possibly modifies, the other consequences of AHR activation.

The importance of kynurenines on bone formation is dependent not only on AHR expression but also on activity in the CTLA-4 and B7-mediated interactions between $\mathrm{T}$ cells and DCs. CTLA-4 inhibits $\mathrm{T}$ cell activation by blocking the interaction between the $\mathrm{T}$ cell receptor co-activator CD28 and the B7 (CD80/CD86) complex. This results in increased generation of Wnt-10b which promotes bone formation (61).

The activation of IDO in DCs is also regulated by the B7 complex, with activation by CTLA-4 expressed on Tregs producing a tolerogenic profile in the DCs. The loss of bone tissue which follows the menopause or ovariectomy has been associated with increased activity in DCs, but preventing CTLA-4 activity preserves bone tissue (62), suggesting a potential use of the stable, synthetic construct CTLA-4Ig in reducing osteoporosis. As with several other instances of IDO and kynurenine involvement in pathology, it remains uncertain whether the modulation of DC activity is via local changes in tryptophan concentration or the generation of pro-apoptotic compounds such as $3 \mathrm{HK}$ and $3 \mathrm{HAA}$.

In addition, CTLA- 4 acts directly on the CD80/86 proteins on monocytes to inhibit their differentiation to osteoclasts, resulting in reduced bone destruction (63-66). Clearly, with such a range of sites of action for CTLA-4 and CTLA-4Ig, some of which influence bone formation and destruction, it is uncertain how important the regulation of kynurenine and its catabolites is to the overall control of bone formation in health or disease. In particular, it is not known whether changes in the concentration of any components of the kynurenine pathway are able to modulate any of the interactions between CD28, CD80, CD86, and CTLA-4. In view of the growing use of CTLA-4Ig in RA, and of the CTLA-4 blocking antibody ipilimumab in melanomas, however, these questions might be worthy of investigation. It is tempting to speculate on the range of studies that, while not specifically examining the actions of kynurenine and its metabolites, nonetheless have generated results which might contribute to understanding the full extent of tryptophan metabolite involvement. Thus, while the anabolic steroid dehydroepiandrosterone increased osteoblastogenesis and bone formation, it also increased the numbers of FoxP3 + Treg cells, an effect that might be generated via kynurenine pathway activation (67).

Finally it is interesting to note that bone formation may be affected indirectly by changes in vitamin $\mathrm{D}$ metabolism. Benzo[a]pyrene, for example promotes the catabolism of the vitamin and would thus hinder calcium absorption and bone formation (68). This would certainly be an important consideration for individuals concerned about osteoporosis following many years of cigarette use. It would be of great interest to determine whether these effects are the result of benzo[a]pyrene activation of AHRs and the subsequent activation of IDO or TDO.

\section{Atherosclerosis}

The overall anti-inflammatory effect of kynurenine in arthritis is reflected in similar properties in several other peripheral disorders. Atherosclerosis is characterized by vascular endothelial deposits known as plaques in which accumulated leukocytes are tightly enmeshed with a calcified complex of fatty materials, blood cells and platelets. These plaques reduce the effective diameter of the vascular lumen, restricting blood flow and affecting blood pressure and tissue viability as a result (69). Atherosclerosis is a major risk factor for disability and mortality and a full understanding of the underlying causative factors remains uncertain. Although the regulation of cholesterol metabolism by apoenzyme-E (ApoE) is believed to play a prominent role in the disorder, rodents specifically lacking ApoE exhibit little vascular abnormality. When ApoE deficiency is combined with the deletion or inhibition of IDO1, however, there is a marked exacerbation of the pathology, as noted above in arthritis, with the deposition of atherosclerotic plaques comparable to the natural disorder in humans $(69,70)$. The importance of IDO activation has been demonstrated by reports that the promotion of Treg differentiation by IDO-expression 
tolerogenic DCs produces a reduction in atherosclerotic plaque deposition $(71,72)$.

Consistent with the studies on trypanosomiasis described below (section Psychiatric Disorders), in which kynurenine levels were positively correlated with IL-10, down-regulation of IDO1 in the atherosclerosis model resulted in a diminished expression of IL-10 in most lymphoid tissues including peripheral blood, spleen and lymph node B cells (69). However, there is not a simple cause-and-effect relationship between these compounds since IL-10 expression was not induced or elevated by kynurenine administration in vivo. On the other hand, kynurenine did increase IL-10 production by B cells in vitro (69).

Not only are these results interesting in terms of understanding the importance of IDO activity in maintaining immune tolerance and thus restraining the extent of disease, but they support the possible explanation of some apparently conflicting results noted above. If the kynurenine induction or promotion of IL-10 expression is specifically exerted on B cells, the overall relationship between the two compounds will depend on the relative involvement of T cells, B cells and probably other leukocyte populations, as stated earlier.

\section{CENTRAL NEURO-INFLAMMATION}

Understanding the role of kynurenines in the Central Nervous System (CNS) has involved work in two areas of tissue function which are more problematic in this region than elsewhere. The first is the question of pathway localization at the cellular level. Detailed histological studies on the presence and distribution of the various enzymes along the kynurenine pathway revealed a differential localization in cell types. For example, KMO was absent from astrocytes $(73,74)$, so that these cells are only able to generate the glutamate antagonist and neuroprotective kynurenic acid. In contrast, microglia express all components of the pathway, so that their activation by inflammatory mediators could result in increased levels of quinolinic acid. This is consistent with the phenotypic resemblance of microglial cells to that of resident phagocytes in other organs, as macrophages also convert tryptophan to all components of the kynurenine pathway including quinolinic acid (74-76). The ability to generate quinolinic acid and other damaging kynurenines such as $3 \mathrm{HK}$, explains why the inflammatory activation of microglia could cause local cellular damage or death. As IDO1 was constitutively active in most glial cells $(74,77)$, it had not been clear why the generation of quinolinic acid would not produce a significant ongoing loss of cells. That could now be understood as the result of kynurenine and kynurenic acid production by astrocytes which-in the absence of KMO and downstream enzymescould accumulate these compounds to a level at which they could antagonize glutamate and quinolinic acid to prevent neural over-excitation and excitotoxicity $(73,77)$. Kynurenine crosses cell membranes readily and kynurenic acid, despite its poor membrane permeability, also enters the extracellular space $(78,79)$. Whether this is simply the result of slow diffusion, a facilitated transfer by pinocytosis or the excretion of kynurenate in exosomes, remains unclear.
There remains significant debate on this hypothesis, as quinolinic acid synthesis by activated microglia may exceed kynurenate production, resulting in local cell damage. In such an inflammatory situation, IDO will also be activated in astrocytes and the increased production of kynurenine-in view of its higher membrane permeability-could well diffuse into the activated microglia much more rapidly than would kynurenic acid. The result could be a potentiation of microglial kynurenine metabolism with even greater levels of quinolinic acid being produced.

Interestingly, the expression of KAT can also vary between cell types in the CNS. Microglia express lower levels of the more active KAT2 relative to KAT1 (73) so that the conversion of kynurenine to quinolinic acid in these cells will be further enhanced relative to cells expressing more of this enzyme. Subtle differences such as these between cell types may be critical in regulating the relative production of different kynurenine metabolites depending on the balance of neural and glial cell activity under any given functional circumstances such as different cytokine profiles.

\section{Huntington's Disease}

The term "central neuro-inflammation" encompasses several disorders in which the initiating defect involves neurons or glial cells but which results in abnormal functioning of the nervous system as a whole. One such disorder is Huntington's disease which can now be understood in terms of newly recognized interactions between kynurenines and aspects of immune function and which may contribute to their roles in physiology and disease pathogenesis.

In the CNS many of the pathological effects of kynurenine pathway activity may result from a balance between the concentrations of quinolinic acid, an agonist at glutamate receptors sensitive to $\mathrm{N}$-methyl-D-aspartate (NMDA) $(4,6,80)$ and kynurenic acid, an antagonist at glutamate receptors but with greatest efficacy blocking NMDA receptors $(5,81,82)$. An excess of the former may result in excessive depolarization, calcium influx and neurotoxicity (83), leading to the speculation that an over-production or suppressed removal of quinolinate might be a factor in neurodegenerative disorders such as Huntington's disease with a possibly similar role in Alzheimer's disease and other central disorders $(84,85)$.

In addition, over-activation of NMDA receptors is accompanied by increased microglial proliferation and activation together with cytokine production. This indicates that an inflammatory environment has been induced in which the levels of potentially pathogenic cytokines are likely to cause, or contribute to the induction of neuronal damage or death $(86,87)$. Consistent with this idea, the levels of quinolinic acid in the CNS are increased by at least two orders of magnitude during and following viral infection $(88,89)$, or following exposure of experimental animals to Toll-Like Receptor agonists such as bacterial lipopolysaccharides (LPS) or viral-RNA-mimetic poly(I:C). These phenomena recall the induction and activation of the kynurenine pathway by IFN- $\gamma$ (1) and the importance of these phenomena in host responses to infection, the protection of allogeneic embryos or the maintenance of tissue grafts resulting 
from the depletion of tryptophan and generation of kynurenine catabolites (2, 3, 90-92).

It is now clear that there are also major changes in the immune system associated with some central disorders, of which Huntington's disease represents a good example. Huntington's disease is a genetic, inherited disorder in which the early degeneration of striatal regions produces progressive motor disorders and later cortical involvement leading to cognitive dysfunction. It is one of few conditions in which involvement of the kynurenine pathway has been implicated on the basis of studies on prokaryotes, in vitro and in vivo mammalian models and human patients (93-95) and for which the kynurenine pathway has been considered as a therapeutic target (96-98). Increasingly, evidence indicates parallel disturbances in the immune system $(94,99-102)$. Central microglia are activated and peripheral monocytes of patients with Huntington's disease are hyper-sensitive to immunogenic stimuli (103). A variety of changes in cytokine expression have been reported in the disorder $(100,104)$ and it is claimed that immunosuppressant treatment can produce significant amelioration of Huntington's disease symptoms and progression (105).

Particularly intriguing is the finding that soluble Human Leucocyte Antigen-G (sHLA-G) levels in the serum of patients show a clear trend of correlation with symptom severity, and a statistically significant effect in the most severely affected patients (100). HLA-G has been associated primarily with materno-fetal tolerance (106) but elevated HLA-G expression has been noted in several CNS disorders in which its effects are largely immunesuppressant $(107,108)$. The full importance of this was not appreciated at the time of the original study, but the molecule is of great interest since it is a secreted protein with the ability to inhibit T cell and cytotoxic cell activity (109).

sHLA-G also promotes the differentiation of Treg cells (110), the effect of which is to enhance the progression and metastasis of tumors. IDO expression is greater in tumors than normal tissue so that these two molecules-IDO and sHLA-G-might act synergistically as tumor promoters. Such synergism might explain the poor performance of selective IDO1 inhibitors in clinical oncogenic trials (111-113). Since IDO1 and sHLA-G are not restricted to the cell membrane or cytoplasm, but can be released into the extracellular medium, their immunosuppressant activity will be exerted around a wider cellular environment than would otherwise be the case with corresponding implications for generalized inflammation and tumor surveillance.

Importantly, it has been proposed that under some circumstances, especially in the presence of high concentrations of IFN- $\gamma$, the major immunosuppressive activity of activated DCs may be mediated to a greater extent by the expression and release of sHLA-G than by IDO (114). The inhibition of cytotoxic $\mathrm{CD} 8+\mathrm{T}$ cells is largely prevented by antibody blockade of sHLA$\mathrm{G}$ rather than by IDO inhibition. The relationship between high levels of IFN- $\gamma$ and HLA-G is quite specific since antigen induction is around 20-fold greater than other HLA antigens and neither IL-6 nor IL-10 mediate the effects of interferons on HLA-G expression. It has been suggested that the relative potencies of IDO and HLA-G-mediated immunosuppression might contribute to the dual nature of interferon activity, this being a major Th1 cytokine inducing inflammatory mediators in the early phase of immune responses to stimuli, but exerting an auto-limiting suppression of inflammation in the later phases (115). High concentrations of IFN- $\gamma$ induce HLA-G expression in DCs which are then responsible for cytotoxic T-lymphocyte inhibition. HLA-G also acts on macrophages (116) to promote their differentiation into the M2 phenotype which is characterized by increased CD163 and reduced CD86 expression. Placental and decidual M2 cells are involved in fetal protection against maternal $\mathrm{T}$ cell attack in utero (117-119) with increased activity of IDO1, a known contributor to fetal protection. Overall, therefore, the parallel changes in Huntington's disease severity and sHLA-G expression and their correlation with the genetic mutation (100) may reflect a significant relevance of immune function in the progression of the disorder.

Questions also remain about these relationships, especially that between immune system function in the peripheral and CNS, given that markers of inflammation have been widely reported in the blood and peripheral organs and tissues of patients with Huntington's disease. A version of the mutated huntingtin protein-which is believed to the primary cause of neurodegeneration in Huntington's disease-also induces disturbances to immune function (99) and there are marked similarities in the altered profile of gene expression in the blood cells and neurons of Huntington's disease patients (104). Do these changes arise simultaneously from an undefined factor, or does one act as a trigger for changes in the other? What would happen in patients treated with an anti-inflammatory agent which was confined to the blood and peripheral tissues? Would such a drug break the degeneration-inflammation cycle sufficiently to reduce the symptoms of Huntington's disease or, possibly, halt its progression? Highly relevant to these considerations are reports that the treatment of patients with Huntington's disease using an immune-modulating drug such as glatiramer acetate showed significant beneficial effects (105), emphasizing the need to understand the neuro-immune interactions at the heart of the disorder.

\section{Alzheimer's Disease and Multiple Sclerosis}

In addition to its activation of NMDA receptors, quinolinic can induce the expression of immunologically active molecules in astrocytes including IL-8, Chemokine Ligand-5 (CCL5) and Macrophage Inflammatory Protein-1 (MIP-1) as well as several chemokine receptors such as CXCR4, CXCR6, CCR3, and CCR5 which promote leukocyte attraction across the bloodbrain barrier $(120,121)$. Several of these proteins are increased in the brains of patients with Alzheimer's disease, so the similarity of this activity to the action of $\beta$-amyloid fragments has prompted the suggestion that the kynurenine pathway may be involved in the etiology of this disorder, an idea consistent with the demonstration that amyloid- $\beta$ induces IDO expression $(122,123)$. It is possible that quinolinic acid could initiate a positive feedback cycle of cell activation, further quinolinic acid generation, mediator induction and further activation, from which it may be difficult for cells to escape. Stimulation of NMDA receptors by quinolinic acid stimulates glial proliferation, further enhancing these events $(120,124)$. 
The increased kynurenine pathway activity in Alzheimer's disease $(74,77,125,126)$ has been linked with $\beta$-amyloid production and tau hyperphosphorylation which can be induced by quinolinic acid $(74,77,122,124,127,128)$. There is also good evidence that the kynurenines plays a role in the formation of neurofibrillary tangles and senile plaques (126). IDO1 inhibition suppresses plaque development, neuronal death and cognitive dysfunction (60).

Neurons express ACMSD (Figure 1) and can therefore divert the conversion of 3HAA from quinolinic acid to picolinic which also regulates inflammatory mediator release (129-131). It also prevents some of the deleterious actions of quinolinic acid including its toxicity on cholinergic and dopaminergic neurons (132-134). It has been suggested that this component of the kynurenine pathway is important in the production of suicidal ideation and behavior (135).

Some of these considerations are especially important in multiple sclerosis (MS) where the underlying problem is inflammatory and the products of kynurenine pathway activation, primarily quinolinic acid, are toxic not only to neurons but also to oligodendrocytes, thus contributing to the loss of central myelination. Kynurenine pathway activity is abnormal in patients with MS, suggesting cell activation (136139). In patients with MS or in the animal model of this disorder (experimental autoimmune encephalomyelitis, EAE), IDO1 and KMO are increased $(85,137,140)$ possibly as a result of the high levels of TNF- $\alpha$ and IFN- $\gamma$. IDO inhibition exacerbates EAE severity in mice $(141,142)$. MS appears to be a disorder in which the beneficial effects of kynurenine pathway activation (induction of $\mathrm{T}$ cell tolerance) is in competition with the generation of potentially damaging levels of quinolinic acid $(76,143)$.

The question of membrane permeability by kynurenine is also important in the relationship between kynurenine pathway activity in the peripheral circulation or tissues and the CNS. The stimulation of immune system cells activates several enzymes in the kynurenine pathway which are relevant to the control of leukocyte populations and the balance between pro- and anti-inflammatory cells and their products. At least two of these-quinolinic acid and kynurenic acid, as noted above-can regulate neuronal excitability and plasticity. It could be life-threatening if the delicate CNS control of bodily functions-somatic and autonomic-were to be influenced significantly by the variety of infective, traumatic, allergic or inflammatory changes that involve the peripheral immune system. The brain is protected from these, however, by the blood-brain barrier, across which kynurenine and $3 \mathrm{HK}$ can cross quite readily, but quinolinic acid and kynurenic acid cross very slowly. Indeed, the clinical consequences of intense or chronically elevated levels of peripheral immune system activation appears to be a major factor in several psychiatric disorders such as depression (144) and schizophrenia (145-147) resulting from the altered balance between kynurenic acid and glutamate receptor agonists, including quinolinic acid. Some of these issues have been discussed in detail elsewhere (148). It has been shown that the cerebrovascular cells intimately involved in blood-brain barrier function express elements of the kynurenine pathway. On activation, the vascular endothelial cells and pericytes produce kynurenine which is released from basolateral sites providing a short path to diffuse across into the brain parenchyma. They also synthesize kynurenic acid which, with picolinic acid, are protective by their abilities to block glutamate receptors and to suppress the secretion of inflammatory mediators, respectively. It has been pointed out that these properties of the blood-brain barrier may be critical factors in HIV-Associated Neurocognitive Disorder (HAND) since the kynurenine produced from barrier cells by systemic inflammatory mediators can enter the CNS rapidly in large amounts, being then converted by microglia to quinolinic acid at a rate sufficient to overwhelm kynurenate production or entry. The resulting excitotoxic loss of neurons may than contribute significantly to the emergence of dementia (148).

Quite apart from the neuroimmunological activity of quinolinic acid, it can increase the permeability of the bloodbrain barrier (149-152), an effect intriguingly opposed by kynurenic acid (153). Not only would this allow inflammatory mediators easier access to the CNS cells but it would also facilitate passage of leukocytes directly into the brain parenchyma.

\section{Psychiatric Disorders}

The kynurenine pathway may be involved in several psychiatric disorders, several of which have been reviewed in detail (144146, 154-157). Perhaps the strongest evidence is for a role in schizophrenia $(145,146)$. One issue which has aroused controversy in this area is a claim that the role of kynurenic acid in schizophrenia could involve the block of nicotinic receptors in addition to NMDA receptors. While the levels of kynurenic acid are increased in the CNS and probably contribute to the symptoms of schizophrenia (146) and other CNS disorders involving defective cognition, that claim has not been substantiated and cannot be replicated [see (158)]. Any apparent effect of kynurenic acid on nicotinic receptors appears to be secondary to the effects of nicotinic receptors on the release of glutamate and other neuroactive compounds (158).

There is also very good evidence that activation of the kynurenine pathway is a major factor in the production of depression and related illnesses. Certainly the K/T ratio correlates well with the induction and severity of depressive symptoms following the administration of IDO inducers such as interferon$\beta$ or exposure to stress $(144,154-157)$. The levels of kynurenines are also closely associated with severe depression and the development of suicidal thoughts and behavior (135).

There has been less interest in the role of kynurenines in anxiety disorders, probably because of the difficulties of interpretation in studies of a psychological process which is hard to translate from experimental animals to humans. Nevertheless, there is increasing evidence that the kynurenine pathway is involved in anxiety behaviors, especially related to primary events in the immune system, such as inflammation (159).

\section{Malaria and Trypanosomiasis}

Infective, rather than genetic examples of neuroinflammation are the parasitic infestations of cerebral malaria and trypanosomiasis. Approximately $20 \%$ of people who contract malaria will proceed to develop cerebral malaria, a condition which causes serious 
somatic and psychiatric changes in patients and, in most cases, results in death. Infection of C57BL/6J mice with the strain Plasmodium berghei ANKA generates an animal model in which the cerebrovascular histology and functional involvement closely reproduce these phenomena in humans (160). When treated with $P$. berghei ANKA almost all the tested mice died within 7 days, but animals treated simultaneously with Ro61-8048 (an inhibitor of KMO) survived up to the end of the study at 21 days (160). KMO inhibition increased the endogenous levels of kynurenine and kynurenic acid as reported in other studies (161-164) and seen in KMO-deficient animals $(165,166)$. The blockade of neuronal glutamate receptors by kynurenate was probably the main factor accounting for the protective inhibition of neurotoxicity and animal survival. Although this initial study did not take account of changes in the immune system, the results were sufficiently clear that a similar study was performed subsequently in trypanosomiasis. Here, an animal model was used to assess the infiltration of brain parenchyma and vascular or ventricular endothelia by reactive leukocytes (167). The results indicated that $\mathrm{KMO}$ inhibition was able to reduce significantly the extent of leukocyte infiltration into the brain as well as the histological assessment of neuronal death.

To follow up these results in human patients, levels of kynurenine and its catabolites were measured in the cerebrospinal fluid of patients suffering from trypanosomiasis and the samples were also examined for levels of IL-6 and IL-10. There was a close and highly significant correlation between levels of kynurenine and IL-6, supporting the view that an inflammatory response had been initiated within the CNS. However, there was also a strongly positive correlation between kynurenine and IL-10, a largely immunosuppressive cytokine secreted primarily by anti-inflammatory leukocytes which suppress DC activation and IDO expression. It is not obvious why there should be an increase in IL-10 production associated with tryptophan metabolism, but several other groups have also reported positive relationships between the kynurenine pathway and IL-10 (168-171). In a cohort of healthy young individuals a clear positive association was seen between IL-10 levels and those of kynurenine, the kynurenine: tryptophan ratio, $3 \mathrm{HK}$ and $3 \mathrm{HAA}$ levels (172). A reduction of TNF- $\alpha$ and IL17 expression by mesenchymal stem cells has been associated with increased IL-10 and kynurenine levels (170), although LPS produces parallel increases in TNF- $\alpha$, IL-10, and IDO activity (173).

In other cases kynurenine and IL-10 behave differently. Subjects responding to BCG vaccinations and patients with inflammatory bowel disease have increased kynurenine and IFN$\gamma$ levels but reduced IL-10 as expected of an immune response (174, 175). IDO1 activity has been shown to increase IL-10 production in $\mathrm{B}$ cells, whereas in vitro kynurenine did not do so, implying that another IDO1 product might be involved. A correlation was reported between pro-inflammatory TNF- $\alpha$ and kynurenine levels, whereas the neuroprotective kynurenic acid was correlated with IL-10 levels (176). Indeed kynurenic acid has been reported to increase IL-10 production (177) so whether kynurenine production is positively or negatively related to IL-10 may depend on the balance of B cell, $\mathrm{T}$ cell and monocyte activity in addition to being dependent on activity in different parts of the kynurenine pathway (Figures 1, 2).

Administration of the statin group of drugs reduces IL6 production but increases IL-10 and kynurenine (178). This expected opposite movement of IL-10 and IL- 6 has been observed in IDO1-deficient DCs in which there is the anticipated loss of AHR activity and reduced levels of IL-10, but increased IL- 6 and TNF- $\alpha$ production (179); conversely both IL- 6 and IL-10 were increased after surgery (180). Kynurenine itself suppresses IL-6 release but kynurenic acid has been reported to increase it. Since both compounds increase IL-10 production, the ratio between kynurenine and kynurenic acid may be a particularly important factor in determining the inflammatory cytokine balance (181).

Nevertheless, despite their opposite immune system bias, IL6 and IL-10 have been shown to change in parallel in patients with depression, in which inflammatory drive (IFN- $\gamma, \mathrm{TNF}-\alpha$, CRP) is reduced. In this same condition IDO activation increases kynurenine concentrations, producing a negative correlation with the cytokines (182). Parallel increases in IL-6 and IL-10 were observed in patients with obsessive-compulsive disorder (183) and chronic hepatitis where the correlation between levels of these proteins was particularly high $(P=0.005)$ (184). Those changes were not accompanied by any change in IFN$\gamma$ levels, perhaps indicating a critical role of IDO metabolites and the IL-6:IL-10 balance in the regulation of IFN- $\gamma$. It may be relevant that expression of the IL-10 receptor is also affected by tryptophan catabolites, since it is increased by IFN- $\gamma$ stimulation and activation of AHRs by kynurenine regulates activity of the promoter region of the IL-10 receptor $\alpha$-subunit to increase receptor expression (185).

Increasing evidence indicates that IDO activation and IL10 production can be induced by the same stimuli, leading to the view that the anti-inflammatory and tolerogenic actions of both proteins may be at least complementary and potentially synergistic (186, 187). Functionally, IDO and IL-10 show important interactions with some degree of mutual redundancy. Thus, amniotic fluid stem cells which are closely related to mesenchymal stem cells and possess the same profile of molecular markers, powerfully suppress the proliferation of peripheral blood mononuclear cells induced by phorbol-12-myristate-13acetate (PMA). This inhibition is mediated by the combination of IDO and IL-10 production by the amniotic cells, with both being required for maximal suppression of proliferation (188).

The relationship between IDO and IL-10 may be particularly relevant in the presence of microbial invasion since some bacteria can induce DCs to facilitate IL-10 production by subpopulations of $\mathrm{T}$ cells such as the FoxP3-negative Tr1-like cells. This is achieved by the microbial induction of appropriate $\mathrm{T}$ cell polarizing molecules including IDO1 (189). Consistent with the overall anti-inflammatory balance which this generates, the production of IDO1 and IL-10 is accompanied by a reduction in the secretion of pro-inflammatory TNF- $\alpha$ and IL-12 components. The simultaneous presence of IDO1 and IL-10 can also influence non-infective inflammation such as that associated with tumor development. For many tumors, it is recognized that compounds with characteristics of Damage-Associated Molecular Patterns in the local microenvironment promote tolerogenic dendritic and 
mesenchymal stem cells which in turn induce the stable coexpression of IDO and IL-10 to further suppress lymphocyte aggression (190). Among the compounds able to initiate this activity are uric acid and the S100A4 protein, both of which have been linked to a variety of inflammatory states in peripheral and central tissues.

\section{ENVIRONMENTAL FACTORS AND THE KYNURENINE PATHWAY: DEVELOPMENT AND EPIGENETICS}

It is a common experience that the existence and severity of arthritic symptoms can vary substantially throughout life, at different times of day, with changes in affective status (mood, stress, anxiety etc.) or with changes in dietary habits. It is important to recognize, therefore, that many such factors do impact directly on the kynurenine pathway and could modulate inflammatory symptoms, peripheral, or central. Exposure to stressful conditions activates the hypothalamo-pituitary-adrenal axis leading to the secretion of corticosteroids which are potent inducers of TDO and will therefore increase kynurenine pathway activity. Cruciferous vegetables in particular contain alkaloids such as brassinins which inhibit IDO1 (191) and a variety of indole-derived compounds such as indole-3-carbinol and di-indolyl-methane which are agonists at AHRs (192, 193), thus regulating the IDO/TDO-kynurenine-AHR feedback cycle described above and giving the compounds significant antiinflammatory properties $(194,195)$. The influence of such factors may be of paramount importance in determining the occurrence and severity of arthritis and related disorders, since we have demonstrated a role of the kynurenine pathway in tissue development of the embryo, and the methylation state of IDO1 appears to determine the magnitude of induced arthritis.

\section{Embryonic Development}

The normal, physiological roles of the kynurenine pathway have received less attention than their potential pathological relevance but recent reports have indicated the probability of important functions in early development of the embryo. The treatment of pregnant rats in late gestation with an inhibitor of KMO (Figure 1), results in an accumulation of kynurenine as well as promoting its transamination to kynurenic acid. These changes resulted in significant molecular, structural, immunocytochemical and functional (electrophysiological) changes in neonates produced by the treated dams and changes in all these parameters persisted into adulthood (161164). Similar results were obtained by the administration of kynurenine itself to pregnant animals (196-199), and in animals lacking KMO by genetic manipulation $(165,166)$.

These results indicate that the kynurenine pathway is playing a significant role in early development and the initial hypothesis to explain these effects was based on the known importance of glutamate and its receptors in the early formation of the brain. In particular, the NMDA-sensitive subtype of receptors are involved in neurogenesis, progenitor cell migration, axon and dendrite growth and guidance as well as spine and synapse formation.
The activity of these NMDA receptors-and therefore brain development-would be dependent on the ratio of the NMDA receptor agonist quinolinic acid and the antagonist kynurenic acid. The occurrence and long-term maintenance of altered brain structure and function might contribute to the development of neurological and psychiatric disorders in adult life. The most established examples of such "neurodevelopmental" disorders are schizophrenia $(145-147,197,199,200)$ and major depression $(154,155)$ including suicide vulnerability (135).

If these changes in CNS development are mirrored in the actions of kynurenines on the immune system, they could contribute significantly to immune system responses and to the susceptibility of offspring to a range of immunological problems including autoimmune diseases such as RA. Thus, in the brain development studies there may have been changes in immune function mediated by the altered levels of kynurenines, such as abnormal cytokine or chemokine levels in the pregnant dam or embryonic brain, changes to microglial activation, or modifications to peripheral leukocyte function and their infiltration into the pre- or postnatal brain. Any effects of prenatal interference with the kynurenine pathway on immune function would represent a highly important area of investigation, especially in the light of evidence that some leukocyte populations express NMDA receptors and other targets of kynurenine and its catabolites such as AHRs and the G-protein coupled receptor GPR35 (82).

While there is a growing literature on the effects of prenatal inflammatory stimuli on CNS development and function in the adult offspring (161-164, 201-204), few studies have yet addressed the immunological consequences of such maternal factors. In one such study, however, it is clear that prenatal activation of the maternal immune system using bacterial LPS or the viral mimetic poly(inosinic:cytidylic) acid (poly[I:C], PIC) can affect the concentrations of several cytokines in the offspring in parallel with changes in expression of IDO (205). The most interesting result of this study was that a repeat immunological challenge in adulthood produced less change in the test animals than controls, indicating a longlasting and possibly permanent depression of immune system function which could have significant implications for the development of autoimmune disease. However, a previous study reached the opposite conclusion, that prenatal immune activation induced increased adaptive immune responses in the offspring (206) raising the possibility that subtle differences in experimental animals or procedures may have a major influence on the outcome.

While these factors do not fall under the classification of "epigenetic" they will clearly interact with epigenetic processes described below in determining the final, overall activity and effectiveness of the kynurenine pathway in neurological and immunological function in postnatal life.

\section{Epigenetics of IDO}

If the kynurenine pathway is as widely and fundamentally important as the above discussions imply, any modifications to the various components of the pathway would carry substantial implications for a variety of disorders. Relevant changes could 
include genetic mutations or epigenetic changes. The latter do not involve changes directly to the genetic machinery or nucleotide sequence, but consist of minor changes to the gene or related segments of the chromosome such as promoter sequences, which alter the functionality of that gene. This may change the extent to which a section of gene is transcribed, or the properties of the transcribed protein. Epigenetic changes are often the result of environmental factors (diet, stress, disease) which affect the activity of key enzymes such as acetyl- or methyldonors, altering their activity on the genome. Epigenetic changes are often reversible but, if they affect the germ-line cells, they may be inherited.

Several of the disorders discussed above may be susceptible to epigenetic influences. The brains of patients with Huntington's disease exhibit evidence of alterations in methylation status $(207,208)$ or acetylation status (209) and inhibition of a histone deacetylase may prevent the development of cognitive deficits as well as huntingtin expansion (210). Such changes may contribute significantly to the course of the disorder and its heritability, especially since DNA methylation has been shown to produce extension of the mutant CAG repeat sequence (211).

RA may involve defects in acetylation (212), reflected in the beneficial activity of a histone deacetylase inhibitor in CIA (213). It is also likely that there are changes in DNA methylation (214-217) as has been noted in regulatory $T$ cells (218) and synovial fibroblasts (219). The methylation pattern has been claimed to reflect therapeutic efficacy of the TNF- $\alpha$ inhibitor etanercept (220) and so may be relevant to explaining the nonresponsiveness to this drug of some patients.

The aberrant methylation of Treg cells, affecting the FOXP3 and CTLA4 genes, reduces their immunosuppressant activity. We have found that the DNA-demethylating compound decitabine reduces this suppression and restores immunosuppression associated with increased expression of Treg markers. In the CIA model of arthritis decitabine increased the suppression function of Treg cells along with a decrease in pro-inflammatory Th1 and Th17 cells and their infiltration into arthritic paws. Of major relevance to the kynurenine pathway, these effects of demethylation were associated with increased expression of IDO1 which is normally an important aspect of the immunosuppressant behavior of Treg cells mediated by the CTLA-4 ligation of B7 proteins, and further differentiation of Treg cells by the promotion of FoxP3 expression.

When CIA was induced in IDO1-deficient mice on a C57/BL6N.Q (H-2 ${ }^{\mathrm{q}}$ ) background), decitabine administration reduced both the early symptoms and pathology of the disorder but also reduced the expression of transcription factors characterizing pro-inflammatory cells (IFN $\gamma+$ and Tbet $^{+}$in Th1; IL17+ and RoR $\gamma \mathrm{t}^{+}$in Th17 cells). In contrast, symptoms were exacerbated in the later stages of disease in parallel with a loss of $\mathrm{FoxP}^{+}$Tregs and an increased number of Tbet $^{+}$Th1 and RoR $\gamma t^{+}$Th17 cells. This time course would be consistent with the concept that IDO1 activity is a critical feature of the interactions needed to maintain long-term Tregmediated immune tolerance. Decitabine also increased the number of IDO1-positive monocytes while a combination of
ADC/decitabine and IFN- $\gamma$ allowed myeloid DCs to increase their IDO1 expression.

Overall, because of its critical, central role in immune function and tolerogenesis, the methylation of IDO1 appears to be an important factor in determining its activity. If these factors affect germline DNA, as noted above, they may significantly affect the immunological competence of offspring and their susceptibility to a range of disorders.

\section{CLINICAL POTENTIAL}

This review has introduced a few of the many disorders afflicting peripheral tissues or the CNS in which inflammation is implicated, but that is enough to recognize the therapeutic potential of influencing the kynurenine pathway by pharmacological interference. Many academic and commercial laboratories have demonstrated the promise of analogs or derivatives of kynurenine and its catabolites to act as receptor agonists, antagonists or enzyme inhibitors $(138,221,222)$.

In the CNS work has been concentrated on inhibitors of KMO to reduce quinolinic acid synthesis and thereby reduce neural activity and excitotoxicity in neurodegenerative disorders as well as in the suppression of peripheral inflammation, especially in the pancreas (223-226). A different approach is in the development of KAT inhibitors intended to reduce kynurenic acid formation in psychiatric disorders such as schizophrenia (227-230). Of course these two approaches, being essentially contrary in their objectives, raise concerns that schizoid symptoms might be induced in response to KMO inhibition, or that KAT inhibition could divert more kynurenine via KMO to quinolinic acid.

In a similar vein, there has been a major effort to develop inhibitors of IDO1 to prevent the immune-suppressant activity of this enzyme and thus to drive tumor cell death or to facilitate the effects of anti-tumor drugs (231-235). In principle, this approach might lead to the initiation or exacerbation of clinical inflammatory and autoimmune disorders described above. While this would remain a problem which would need careful monitoring, clinical trials with IDO1 inhibitors have recently been found to be less effective anti-cancer agents than anticipated (111-113), raising doubts about the continuation of this strategy.

Despite these concerns, major advances are being made in kynurenine-related treatments for Huntington's disease and schizophrenia, and the range of conditions potentially amenable to kynurenine-related therapy continues to escalate. The factors which can recruit kynurenine pathway involvement such as infection, inflammation, dietary changes, various forms of stress and others make it highly likely that the kynurenine pathway will prove to be a valuable source of new therapeutic agents in the near future.

\section{SUMMARY AND CONCLUSIONS}

Some of the inter-relationships between IDO or its kynureninederived catabolites and aspects of the immune system have been 
discussed, focusing on several examples of disorders affecting peripheral tissues or the CNS. In many cases there are important questions to be resolved, such as which components of the kynurenine pathway are responsible for different elements of immune regulation. It seems likely that a fuller appreciation of these issues will not only help to understand the molecular basis of some disorders, but will further the development of increasingly sophisticated and targeted therapies (236). This will be especially important if methods can be identified to modify or prevent epigenetic changes which alter the expression or functional capacity of relevant enzymes, receptors or transduction systems. Finally, more detailed investigation of the immunological consequences of stress, infection and immune system activation during pregnancy-all of which involve activity in the kynurenine pathway-may be highly relevant to understanding postnatal susceptibility to autoimmune disorders and cancer, much as recent work has shown lasting effects on

\section{REFERENCES}

1. Yoshida R, Imanishi J, Oku T, Kishida T, Hayaishi O. Induction of pulmonary indoleamine 2,3-dioxygenase by interferon. Proc Nat Acad Sci USA. (1981) 78:129-32. doi: 10.1073/pnas.78.1.129

2. Munn DH, Zhou M, Attwood JT, Bondarev I, Conway SJ, Marshall B, et al. Prevention of allogeneic fetal rejection by tryptophan catabolism. Science. (1998) 281:1191-3. doi: 10.1126/science.281.538 0.1191

3. Mellor AL, Munn DH. Immunology at the maternal-fetal interface: lessons for T cell tolerance and suppression. Ann Rev Immunol. (2000) 18:367-91. doi: 10.1146/annurev.immunol.18.1.367

4. Stone TW, Perkins MN. Quinolinic acid: a potent endogenous excitant at amino acid receptors in CNS. Eur J Pharmacol. (1981) 72:411-2. doi: 10.1016/0014-2999(81)90587-2

5. Perkins MN, Stone TW. An iontophoretic investigation of the actions of convulsant kynurenines and their interaction with the endogenous excitant quinolinic acid. Brain Res. (1982) 247:184-7. doi: 10.1016/0006-8993(82)91048-4

6. Perkins MN, Stone TW. Pharmacology and regional variations of quinolinic acid-evoked excitations in the rat central nervous system. J Pharmacol Exp Ther. (1983) 226:551-7.

7. Fatokun AA, Hunt NH, Ball HJ. Indoleamine 2,3-dioxygenase 2 (IDO2) and the kynurenine pathway: characteristics and potential roles in health and disease. Amino Acids. (2013) 45:1319-29. doi: 10.1007/s00726-013-1602-1

8. Criado G, Simelyte E, Inglis JJ, Essex D, Williams RO. Indoleamine 2,3 dioxygenase-mediated tryptophan catabolism regulates accumulation of Th1/Th17 Cells in the joint in collagen-induced arthritis. Arthritis Rheum. (2009) 60:1342-51. doi: 10.1002/art.24446

9. Onodera T, Jang MH, Guo ZJ, Yamasaki M, Hirata T, Bai ZB, et al. Constitutive expression of IDO by dendritic cells of mesenteric lymph nodes: functional involvement of the CTLA-4/B7 and CCL22/CCR4 interactions. $J$ Immunol. (2009) 183:5608-14. doi: 10.4049/jimmunol.0804116

10. Cribbs AP, Kennedy A, Penn H, Read JE, Amjadi P, Green P, et al. Treg cell function in rheumatoid arthritis is compromised by CTLA-4 promoter methylation resulting in a failure to activate the indoleamine 2,3-dioxygenase pathway. Arthritis Rheumatol. (2014) 66:2344-54. doi: 10.1002/art.38715

11. DiNatale BC, Murray IA, Schroeder JC, Flaveny CA, Lahoti TS, Laurenzana EM, et al. Kynurenic acid is a potent endogenous aryl hydrocarbon receptor ligand that synergistically induces interleukin-6 in the presence of inflammatory signaling. Toxicol Sci. (2010) 115:89-97. doi: 10.1093/toxsci/kfq024

12. Nguyen NT, Kimura A, Nakahama T, Chinen I, Masuda K, Nohara $\mathrm{K}$, et al. Aryl hydrocarbon receptor negatively regulates dendritic cell the nervous system. With growing interest in the importance of neuroimmune interactions for disease development and resolution, a combined knowledge of both these areas might yield synergistic advances in medicine and therapeutics.

\section{AUTHOR CONTRIBUTIONS}

All authors contributed to the writing and proof-reading of this manuscript.

\section{ACKNOWLEDGMENTS}

The authors acknowledge personal support from the Ministry of Science and Technology (Taiwan)(Y-SH) and Cancer Research UK (FC); JO was a vs. Arthritis Postdoctoral Research Fellow. TS is an Honorary Senior Research Fellow. immunogenicity via a kynurenine-dependent mechanism. Proc Nat Acad Sci USA. (2010) 107:19961-6. doi: 10.1073/pnas.1014465107

13. Nakahama T, Kimura A, Nguyen NT, Chinen I, Hanieh H, Nohara K, et al. Aryl hydrocarbon receptor deficiency in T cells suppresses the development of collagen-induced arthritis. Proc Nat Acad Sci USA. (2011) 108:14222-7. doi: $10.1073 /$ pnas. 1111786108

14. Li Q, Harden JL, Anderson CD, Egilmez NK. Tolerogenic phenotype of IFN-g-induced IDO+ dendritic cells is maintained via an autocrine IDO-kynurenine/ AhR-IDO loop. J Immunol. (2016) 197:962-70. doi: 10.4049/jimmunol.1502615

15. Xie FT, Cao JS, Zhao J, Yu Y, Qi F, Dai XC. IDO expressing dendritic cells suppress allograft rejection of small bowel transplantation in mice by expansion of Foxp3(+) regulatory T cells. Transpl Immunol. (2015) 33:69-77. doi: 10.1016/j.trim.2015.05.003

16. Fallarino F, Grohmann U, You S, McGrath BC, Cavener DR, Vacca C, et al. The combined effects of tryptophan starvation and tryptophan catabolites down-regulate $\mathrm{T}$ cell receptor zeta-chain and induce a regulatory phenotype in naive T cells. J Immunol. (2006) 176:6752-61. doi: 10.4049/jimmunol.176.11.6752

17. Fallarino F, Grohmann U. Using an ancient tool for igniting and propagating immune tolerance: IDO as an inducer and amplifier of regulatory T cell functions. Curr Med Chem. (2011) 18:2215-21. doi: $10.2174 / 092986711795656027$

18. Romani L, Fallarino F, de Luca A, Montagnoli C, D'Angelo C, Zelante T, et al. Defective tryptophan catabolism underlies inflammation in mouse chronic granulomatous disease. Nature. (2008) 451:211-5. doi: 10.1038/nature06471

19. Romani L, Zelante T, de Luca A, Fallarino F, Puccetti P. IL-17 and therapeutic kynurenines in pathogenic inflammation to fungi. J Immunol. (2008) 180:5157-62 doi: 10.4049/jimmunol.180.8.5157

20. Cheng L, Qian L, Xu ZZ, Tan Y, Luo CY. Aromatic hydrocarbon receptor provides a link between smoking and rheumatoid arthritis in peripheral blood mononuclear cells. Clin Exp Rheumatol. (2019) 37:445-9.

21. Talbot J, Peres RS, Pinto LG, Oliveira RDR, Lima KA, Donate $\mathrm{PB}$, et al. Smoking-induced aggravation of experimental arthritis is dependent of aryl hydrocarbon receptor activation in Th17 cells. Arthritis Res Ther. (2018) 20:119. doi: 10.1186/s13075-0181609-9

22. Nguyen NT, Nakahama T, Kishimoto T. Aryl hydrocarbon receptor and experimental autoimmune arthritis. Semin Immunopathol. (2013) 35:63744. doi: 10.1007/s00281-013-0392-6

23. Nii T, Kuzuya K, Kabata D, Matsui T, Murata A, Ohya T, et al. Crosstalk between tumor necrosis factor-alpha signaling and aryl hydrocarbon receptor signaling in nuclear factor -kappa B activation: a possible molecular mechanism underlying the reduced efficacy of TNF-inhibitors 
in rheumatoid arthritis by smoking. J Autoimmun. (2019) 98:95-102. doi: 10.1016/j.jaut.2018.12.004

24. Fu J, Nogueira SV, van Drongelen V, Coit P, Ling S, Rosloniec EF, et al. Shared epitope-aryl hydrocarbon receptor crosstalk underlies the mechanism of gene-environment interaction in autoimmune arthritis. Proc Nat Acad Sci USA. (2018) 115:4755-60. doi: 10.1073/pnas.1722124115

25. Tong B, Yuan X, Dou Y, Wu X, Wang Y, Xia Y, et al. Sinomenine induces the generation of intestinal Treg cells and attenuates arthritis via activation of aryl hydrocarbon receptor. Lab Invest. (2016) 96:1076-86. doi: 10.1038/labinvest.2016.86

26. Tong B, Yuan X, Dou Y, Wu X, Chou G, Wang Z, et al. Norisoboldine, an isoquinoline alkaloid, acts as an aryl hydrocarbon receptor ligand to induce intestinal Treg cells and thereby attenuate arthritis. Int J Biochem Cell Biol. (2016) 75:63-73. doi: 10.1016/j.biocel.2016.03.014

27. Yuan X, Tong B, Dou Y, Wu X, Wei Z, Dai Y. Tetrandrine ameliorates collagen-induced arthritis in mice by restoring the balance between Th17 and Treg cells via the aryl hydrocarbon receptor. Biochem Pharmacol. (2016) 101:87-99. doi: 10.1016/j.bcp.2015.11.025

28. Ogando J, Tardaguila M, Diaz-Alderete A, Usategui A, Miranda-Ramos V, Jorge Martinez-Herrera D, et al. Notch-regulated miR-223 targets the aryl hydrocarbon receptor pathway and increases cytokine production in macrophages from rheumatoid arthritis patients. Sci Rep. (2016) 6:20223. doi: $10.1038 /$ srep 20223

29. Lahoti TS, Hughes JM, Kusnadi A, John K, Zhu B, Murray IA, et al. Aryl hydrocarbon receptor antagonism attenuates growth factor expression, proliferation, and migration in fibroblast-like synoviocytes from patients with rheumatoid arthritis. J Pharmacol Exp Ther. (2014) 348:236-45. doi: 10.1124/jpet.113.209726

30. Badawy AA. Kynurenine pathway of tryptophan metabolism: regulatory and functional aspects. Int J Tryptophan Res. (2017) 10:1178646917691938. doi: $10.1177 / 1178646917691938$

31. Badawy AA. Hypothesis kynurenic and quinolinic acids: the main players of the kynurenine pathway and opponents in inflammatory disease. Med Hypoth. (2018) 118:129-38. doi: 10.1016/j.mehy.2018. 06.021

32. Munn DH, Sharma MD, Baban B, Harding HP, Zhang YH, Ron D, et al. GCN2 kinase in T cells mediates proliferative arrest and anergy induction in response to indoleamine 2,3-dioxygenase. Immunity. (2005) 22:633-42. doi: 10.1016/j.immuni.2005.03.013

33. Yan Y, Zhang G-X, Gran B, Fallarino F, Yu S, Li H, et al. IDO upregulates regulatory $\mathrm{T}$ cells via tryptophan catabolite and suppresses encephalitogenic $\mathrm{T}$ cell responses in experimental autoimmune encephalomyelitis. J Immunol. (2010) 185:5953-61. doi: 10.4049/jimmunol.1001628

34. Ravindran R, Khan N, Nakaya HI, Li SZ, Loebbermann J, Maddur MS, et al. Vaccine activation of the nutrient sensor GCN2 in dendritic cells enhances antigen presentation. Science. (2014) 343:313-7. doi: 10.1126/science. 1246829

35. van de Velde LA, Guo XZJ, Barbaric L, Smith AM, Oguin TH, Thomas PG, et al. Stress kinase GCN2 controls the proliferative fitness and trafficking of cytotoxic $\mathrm{T}$ cells independent of environmental amino acid sensing. Cell Rep. (2016) 17:2247-58. doi: 10.1016/j.celrep.2016.10.079

36. Forrest CM, Mackay GM, Oxford L, Stoy N, Stone TW, Darlington LG. Kynurenine pathway metabolism in patients with osteoporosis after two years of drug treatment. Clin Exp Pharmacol Physiol. (2006) 33:1078-87. doi: 10.1111/j.1440-1681.2006.04490.x

37. Baran H, Schwarcz R. Presence of 3-hydroxyanthranilic acid in rat-tissues and evidence for its production from anthranilic acid in the brain. $J$ Neurochem. (1990) 55:738-44. doi: 10.1111/j.1471-4159.1990.tb04553.x

38. Fallarino I, Grohmann U, Vacca C, Bianchi R, Orabona C, Spreca A, et al. T cell apoptosis by tryptophan catabolism. Cell Death Differ. (2002) 9:1069-77. doi: $10.1038 /$ sj.cdd.4401073

39. Pietschmann P, Mechtcheriakova D, Meshcheryakova A, Föger-Samwald U, Ellinger I. Immunology of osteoporosis: a mini-review. Gerontology. (2016) 62:128-37. doi: 10.1159/000431091

40. Iseme RA, Mcevoy M, Kelly B, Agnew L, Walker FR, Attia J. Is osteoporosis an autoimmune mediated disorder? Bone Rep. (2017) 7:121-31. doi: 10.1016/j.bonr.2017.10.003
41. Caetano-Lopes J, Canhão H, Fonseca JE. Osteoimmunology-the hidden immune regulation of bone. Autoimmun Rev. (2009) 8:250-55. doi: 10.1016/j.autrev.2008.07.038

42. Darlington LG, Forrest CM, Mackay GM, Smith RA, Smith AJ, Stoy N, et al. On the biological importance of the 3-hydroxyanthranilic acid: anthranilic acid ratio. Int J Tryptophan Res. (2010) 3:51-9. doi: 10.4137/IJTR.S4282

43. Dykens JA, Sullivan SG, Stern A. Oxidative reactivity of the tryptophan metabolites 3-hydroxyanthranilate, quinolinate and picolinate. Biochem Pharmacol. (1987) 36:211-7.

44. Ishii T, Iwahashi H, Sugata R, Kido R, Fridovich I. Superoxide disumutases enhance the rat of autoxidation of 3-hydroxyanthranilic acid. Arch Biochem Biophys. (1990) 276:248-50. doi: 10.1016/0003-9861(90)90034-V

45. Sternberg JM, Forrest CM, Dalton RN, Turner C, Rodgers J, Stone TW, et al. Kynurenine pathway activation in human african trypanosomiasis. J Infect Dis. (2017) 215:806-12. doi: 10.1093/infdis/jiw623

46. Charconnet-Harding F, Dalgliesh CE, Neuberger A. The relation between riboflavin and tryptophan metabolism, studied in the rat. Biochem J. (1953) 53:513-21. doi: 10.1042/bj0530513

47. Stevens $\mathrm{CO}$, Henderson LM. Riboflavin and hepatic kynurenine hydroxylase. J Biol Chem. (1959) 234:1191-4.

48. Brijal S, Lakshmi AV. Tissue distribution and turnover of $[3 \mathrm{H}]$ riboflavin during respiratory infection in mice. Metabolism. (1999) 48:1608-11. doi: 10.1016/S0026-0495(99)90253-6

49. Menezes RR, Godin AM, Rodrigues FF, Coura GME, Melo ISF, Brito A, et al. Thiamine and riboflavin inhibit production of cytokines and increase the anti-inflammatory activity of a corticosteroid in a chronic model of inflammation induced by complete freund's adjuvant. Pharmacol Rep. (2017) 69:1036-43. doi: 10.1016/j.pharep.2017.04.011

50. Dey S, Bishayi B. Riboflavin along with antibiotics balances reactive oxygen species and inflammatory cytokines and controls Staphylococcus aureus infection by boosting murine macrophage function and regulates inflammation. J Inflamm. (2016) 13:36. doi: 10.1186/s12950-016-0145-0

51. Pinkerton H, Bessey OA. The loss of resistance to murine typhus infection resulting from riboflavin deficiency in rats. Science. (1939) 89:368-70. doi: 10.1126/science.89.2312.368

52. Verdrengh M, Tarkowski A. Riboflavin in innate and acquired immune responses. Inflamm Res. (2005) 54:390-3. doi: 10.1007/s00011-005-1372-7

53. Mulherin DM, Thurnham DI, Situnayake RD. Glutathione reductase activity, riboflavin status, and disease activity in rheumatoid arthritis. Ann Rheum Dis. (1996) 55:837-40. doi: 10.1136/ard.55.11.837

54. Igari T, Tsuchizawa M, Shimamura T. Alteration of tryptophan-metabolism in the synovial-fluid of patients with rheumatoid-arthritis and osteoarthritis. Tohoku J Exp Med. (1987) 153:79-86. doi: 10.1620/tjem.153.79

55. Ge L, Cui Y, Cheng K, Han J. Isopsoralen enhanced osteogenesis by targeting AhR/ER $\alpha$. Molecules. (2018) 23:2600. doi: 10.3390/molecules23102600

56. Michalowska M, Znorko B, Kaminski T, Oksztulska-Kolanek E, Pawlak D. New insights into tryptophan and its metabolites in the regulation of bone metabolism. J Physiol Pharmacol. (2015) 66:779-91.

57. Kalaska B, Pawlak K, Domaniewski T, Oksztulska-Kolanek E, Znorko B, Roszczenko A, et al. Elevated levels of peripheral kynurenine decrease bone strength in rats with chronic kidney disease. Front Physiol. (2017) 8:836. doi: 10.3389/fphys.2017.00836

58. Iqbal J, Sun L, Cao J, Yuen T, Lu P, Bab I, et al. Smoke carcinogens cause bone loss through the aryl hydrocarbon receptor and induction of Cyp1 enzymes. Proc Nat Acad Sci USA. (2013) 110:11115-20. doi: 10.1073/pnas.1220919110

59. Tong Y, Niu M, Du Y, Mei W, Cao W, Dou Y, et al. Aryl hydrocarbon receptor suppresses the osteogenesis of mesenchymal stem cells in collagen-induced arthritic mice through the inhibition of beta-catenin. Exp Cell Res. (2017) 350:349-57. doi: 10.1016/j.yexcr.2016.12.009

60. Yu TY, Pang WJ, Yang GS. 3,3 '-Diindolylmethane increases bone mass by suppressing osteoclastic bone resorption in mice. J Pharmacol Sci. (2015) 127:75-82. doi: 10.1016/j.jphs.2014.11.006

61. Roser-Page S, Vikulina T, Zayzafoon M, Weitzmann MN. CTLA-4IgInduced $\mathrm{T}$ cell anergy promotes Wnt-10b production and bone formation in a mouse model. Arthritis Rheumatol. (2014) 66:990-9. doi: 10.1002/art.38319

62. Grassi F, Tell G, Robbie-Ryan M, Gao Y, Terauchi M, Yang X, et al. Oxidative stress causes bone loss in estrogen-deficient mice through enhanced bone 
marrow dendritic cell activation. Proc Nat Acad Sci USA. (2007) 104:1508792. doi: 10.1073/pnas.0703610104

63. Axmann R, Herman S, Zaiss M, Franz S, Polzer K, Zwerina J, et al. CTLA4 directly inhibits osteoclast formation. Ann Rheum Dis. (2008) 67:1603-9. doi: 10.1136/ard.2007.080713

64. Dubrovsky AM, Lim MJ, Lane NE. Osteoporosis in rheumatic diseases: anti-rheumatic drugs and the skeleton. Calcif Tissue Int. (2018) 102:607-18. doi: 10.1007/s00223-018-0401-9

65. Bozec A, Zaiss MM, Kagwiria R, Voll R, Rauh M, Chen Z, et al. $T$ cell costimulation molecules $\mathrm{CD} 80 / 86$ inhibit osteoclast differentiation by inducing the IDO/Tryptophan pathway. Sci Transl Med. (2014) 6:235ra60. doi: $10.1126 /$ scitranslmed. 3007764

66. Bozec A, Zaiss MM. T regulatory cells in bone remodelling. Curr Osteoporos Rep. (2017) 15:121-5. doi: 10.1007/s11914-017-0356-1

67. Qiu X, Gui Y, Xu Y, Li D, Wang L. DHEA promotes osteoblast differentiation by regulating the expression of osteoblast-related genes and Foxp(3+) regulatory $\mathrm{T}$ cells. Biosci Trends. (2015) 9:307-14. doi: 10.5582/bst.2015.01073

68. Matsunawa M, Amano $\mathrm{Y}$, Endo K, Uno S, Sakaki T, Yamada S, et al. The Aryl hydrocarbon receptor activator benzo[a]pyrene enhances vitamin D-3 catabolism in macrophages. Toxicol Sci. (2009) 109:50-8. doi: 10.1093/toxsci/kfp044

69. Cole JE, Astola N, Cribbs AP, Goddard ME, Park I, Green P, et al. Indoleamine 2,3-dioxygenase- 1 is protective in atherosclerosis and its metabolites provide new opportunities for drug development. Proc Nat Acad Sci USA. (2015) 112:13033-8. doi: 10.1073/pnas.1517820112

70. Polyzos KA, Ovchinnikova O, Berg M, Baumgartner R, Agardh H, Pirault $\mathrm{J}$, et al. Inhibition of indoleamine-2,3-dioxygenase promotes vascular inflammation and increases atherosclerosis in apoE-/- mice. Cardiovasc Res. (2015) 106:295-302. doi: 10.1093/cvr/cvv100

71. Forteza MJ, Polyzos KA, Baumgartner R, Suur BE, Mussbacher M, Johansson DK, et al. Activation of the regulatory T-cell/indoleamine-2,3-dioxygenase axis reduces vascular inflammation and atherosclerosis in hypoerlipidemic mice. Front Immunol. (2018) 9:950. doi: 10.3389/fimmu.2018.00950

72. Yun TJ, Lee JS, Machmach K, Shim D, Choi J, Wi YJ, et al. Indoleamine2,3-dioxygenase-expressing plasmacytoid dendritic cells protect against atherosclerosis by induction of regulatory T cells. Cell Metab. (2016) 23:85266. doi: 10.1016/j.cmet.2016.04.010

73. GuilleminGJ, Kerr SJ, Smythe GA, Smith DG, Kapoor V, ArmatiPJ, et al. Kynurenine pathway metabolism in human astrocytes: a paradox for neuronal protection. J Neurochem. (2001) 78:842-53. doi: 10.1046/j.1471-4159.2001.00498.x

74. Guillemin GJ, Brew BJ, Noonan CE, Takikawa O, Cullen KM. Indoleamine 2,3 dioxygenase and quinolinic acid immunoreactivity in Alzheimer's disease hippocampus. Neuropathol Appl Neurobiol. (2005) 31:395-404. doi: 10.1111/j.1365-2990.2005.00655.x

75. Chiarugi A, Calvani M, Meli E, Traggiai E, Moroni F. Synthesis and release of neurotoxic kynurenine metabolites by human monocyte-derived macrophages. J Neuroimmunol. (2001) 120:190-8. doi: 10.1016/S0165-5728(01)00418-0

76. Heyes MP, Saito K, Markey SP. Human macrophages convert Ltryptophan into the neurotoxin quinolinic acid. Biochem J. (1992) 283:633-5. doi: 10.1042/bj2830633

77. Guillemin GJ, Smythe G, Takikawa O, Brew BJ. Expression of indoleamine 2,3-dioxygenase and production of quinolinic acid by human microglia, astrocytes, and neurons. Glia. (2005) 49:15-23. doi: 10.1002/glia.20090

78. Notarangelo FM, Beggiato S, Schwarcz R. Assessment of prenatal kynurenine metabolism using tissue slices: focus on the neosynthesis of kynurenic acid in mice. Dev Neurosci. (2019) 41:102-11. doi: 10.1159/000499736

79. Heredi J, Cseh EK, Berko A, Magyarine A, Veres G, Zadori D, et al. Investigating kynurenic acid production and kynurenergic manipulation on acute mouse brain slice preparations. Brain Res Bull. (2019) 146:185-91. doi: 10.1016/j.brainresbull.2018.12.014

80. Stone TW. The neuropharmacology of quinolinic and kynurenic acids. Pharmacol Rev. (1993) 45:309-79.

81. Stone TW, Darlington LG. Endogenous kynurenines as targets for drug discovery and development. Nat Rev Drug Discov. (2002) 1:609-20. doi: $10.1038 / \mathrm{nrd} 870$
82. Stone TW, Stoy N, Darlington LG. An expanding range of targets for kynurenine metabolites of tryptophan. Trends Pharmacol Sci. (2013) 34:13643. doi: 10.1016/j.tips.2012.09.006

83. Schwarcz R, Whetsell WO, Mangano RM. Quinolinic acid - an endogenous metabolite that produces axon-sparing lesions in rat brain. Science. (1983) 219:316-8. doi: 10.1126/science.6849138

84. Ting KK, Brew BJ, Guillemin GJ. Effect of quinolinic acid on human astrocytes morphology and functions: implications in Alzheimer's disease. J Neuroinflammation. (2009) 6:36. doi: 10.1186/1742-2094-6-36

85. Lovelace MD, Varney B, Sundaram G, Lennon MJ, Lim CK, Jacobs K, et al. Recent evidence for an expanded role of the kynurenine pathway of tryptophan metabolism in neurological diseases. Neuropharmacology. (2017) 112:373-88. doi: 10.1016/j.neuropharm.2016.03.024

86. Samuelsson AM, Jennische E, Hansson HA, Holmang A. Prenatal exposure to interleukin-6 results in inflammatory neurodegeneration in hippocampus with NMDA / GABA(A) dysregulation and impaired spatial learning. Am J Physiol Regul Integr Comp Physiol. (2006) 290:R1345-56. doi: 10.1152/ajpregu.00268.2005

87. Zou J, Crews FT. Glutamate/NMDA excitoxicity and HMGB1/TLR4 neuroimmune toxicity converge as components of neurodegeneration. AIMS Mol Sci. (2015) 2:77-100. doi: 10.3934/molsci.2015.2.77

88. Heyes MP, Mefford IN, Quearry BJ, Dedhia M, Lackner A. Increased ratio of quinolinic acid to kynurenic acid in cerebrospinal-fluid of d-retrovirusinfected rhesus macaques - relationship to clinical and viral status. Ann Neurol. (1990) 27:666-75. doi: 10.1002/ana.410270614

89. Heyes MP, Jordan EK, Lee K, Saito K, Frank JA, Snoy PJ, et al. Relationship of neurologic status in macaques infected with the simian immunodeficiency virus to cerebrospinal-fluid quinolinic acid and kynurenic acid. Brain Res. (1992) 570:237-50. doi: 10.1016/0006-8993(92) 90587-Y

90. Pfefferkorn ER. Interferon-gamma blocks the growth of toxoplasma-gondii in human-fibroblasts by inducing the host-cells to degrade tryptophan. Proc Nat Acad Sci USA. (1984) 81:908-12. doi: 10.1073/pnas.81.3.908

91. Terness P, Bauer TM, Rose L, Dufter C, Watzlik A, Simon H, et al. Inhibition of allogeneic $\mathrm{T}$ cell proliferation by indoleamine 2,3-dioxygenase-expressing dendritic cells: mediation of suppression by tryptophan metabolites. J Exp Med. (2002) 196:447-57. doi: 10.1084/jem.20020052

92. Terness P, Chuang JJ, Opelz G. The immunoregulatory role of IDOproducing human dendritic cells revisited. Trends Immunol. (2006) 27:6873. doi: 10.1016/j.it.2005.12.006

93. Giorgini F, Guidetti P, Nguyen QV, Bennett SC, Muchowski PJ. A genomic screen in yeast implicates kynurenine 3-monooxygenase as a therapeutic target for Huntington disease. Nat Genet. (2005) 37:526-31. doi: $10.1038 / \mathrm{ng} 1542$

94. Schwarcz R, Guidetti P, Sathyasaikumar KV, Muchowski PJ. Of mice, rats and men: revisiting the quinolinic acid hypothesis of Huntington's disease. Prog Neurobiol. (2010) 90:230-45. doi: 10.1016/j.pneurobio.2009.04.005

95. Stoy N, Mackay GM, Forrest CM, Christofides J, Egerton M, Stone TW, et al. Tryptophan metabolism and oxidative stress in patients with Huntington's disease. I Neurochem. (2005) 93:611-23. doi: $10.1111 / j .1471-4159.2005 .03070 . x$

96. Boros FA, Klivenyi P, Toldi J, Vecsei L. Indoleamine-2,3-dioxygenase as a novel therapeutic target for Huntingon's disease. Exp Opin Ther Targets. (2019) 23:39-51. doi: 10.1080/14728222.2019.1549231

97. Stone TW, Forrest CM, Darlington LG. Kynurenine pathway inhibition as a therapeutic strategy for neuroprotection. FEBS J. (2012) 279:1386-97. doi: 10.1111/j.1742-4658.2012.08487.x

98. Stone TW, Forrest CM, Stoy N, Darlington LG. Involvement of kynurenines in Huntington's disease and stroke-induced brain damage. J Neural Transm. (2012) 119:261-74. doi: 10.1007/s00702-0110676-8

99. Andre R, Carty L, Tabrizi SJ. Disruption of immune cell function by mutant huntingtin in Huntington's disease pathogenesis. Curr Opin Pharmacol. (2016) 26:33-8. doi: 10.1016/j.coph.2015.09.008

100. Forrest CM, Mackay GM, Stoy N, Spiden SL, Taylor R, Stone TW, et al. Blood levels of kynurenines, interleukin-23 and soluble human leucocyte antigen-G at different stages of Huntington's disease. J Neurochem. (2010) 112:112-22. doi: $10.1111 / j .1471-4159.2009 .06442 . \mathrm{x}$ 
101. Ellrichmann G, Reick C, Saft C, Linker RA. The role of the immune system in Huntington's disease. Clin. Dev. Immunol. (2013) 2013:541259. doi: $10.1155 / 2013 / 541259$

102. Sathyasaikumar KV, Stachowski EK, Amori L, Guidetti P, Muchowski PJ, Schwarcz R. Dysfunctional kynurenine pathway metabolism in the R6/2 mouse model of Huntington's disease. J Neurochem. (2010) 113:1416-25. doi: 10.1111/j.1471-4159.2010.06675.x

103. Crotti A, Glass CK. The choreography of neuroinflammation in Huntington's disease. Trends Immunol. (2015) 36:364-73. doi: 10.1016/j.it.2015.04.007

104. Moss DJH, Flower MD, Lo KK, Miller JRC, van Ommen GJB, 't Hoen PA, et al. Huntington's disease blood and brain show a common gene expression pattern and share an immune signature with Alzheimer's disease. Sci Rep. (2017) 7:44849. doi: 10.1038/srep44849

105. Corey-Bloom J, Aikin AM, Gutierrez AM, Nadhem JS, Howell TL, Thomas EA. Beneficial effects of glatiramer acetate in Huntington's disease mouse models: evidence for BDNF-elevating and immunomodulatory mechanisms. Brain Res. (2017) 1673:102-10. doi: 10.1016/j.brainres.2017.08.013

106. Kostlin N, Ostermeir AL, Spring B, Schwarz J, Marme A, Walter CB, et al. HLA-G promotes myeloid-derived suppressor cell accumulation and suppressive activity during human pregnancy through engagement of the receptor ILT4. Eur J Immunol. (2017) 47:374-84. doi: 10.1002/eji.201646564

107. Wiendl H, Feger U, Mittelbronn M, Jack C, Schreiner B, Stadelmann C, et al. Expression of the immune-tolerogenic major histocompatibility molecule HLA-G in multiple sclerosis: implications for CNS immunity. Brain. (2005) 128:2689-704. doi: 10.1093/brain/awh609

108. Fainardi E, Rizzo R, Melchiorri L, Castellazzi M, Paolino E, Tola MR, et al. Intrathecal synthesis of soluble HLA-G and HLA-I molecules are reciprocally associated to clinical and MRI activity in patients with multiple sclerosis. Mult Scler. (2006) 12:2-12. doi: 10.1191/1352458506ms1241oa

109. Abumaree M, Al Jumah M, Pace RA, Kalionis B. Immunosuppressive properties of mesenchymal stem cells. Stem Cell Rev Rep. (2012) 8:375-92. doi: 10.1007/s12015-011-9312-0

110. Nasef A, Mathieu N, Chapel A, Frick J, Francois S, Mazurier $\mathrm{C}$, et al. Immuno-suppressive effects of mesenchymal stem cells: involvement of HLA-G. Transplantation. (2007) 84:231-7. doi: 10.1097/01.tp.0000267918.07906.08

111. Long GV, Dummer R, Humid O, Gajewski TF, Caglevic C, Dalle S, et al. Epacadostat plus pembrolizumab versus placebo plus pembrolizumab in patients with unresectable or metastatic melanoma (ECHO-301/KEYNOTE252): a phase 3, randomised, double-blind study. Lancet Oncol. (2019) 20:1083-97. doi: 10.1016/S1470-2045(19)30274-8

112. Guenther J, Daebritz J, Wirthgen E. Limitations and off-target effects of tryptophan-related IDO inhibitors in cancer treatment. Front Immunol. (2019) 10:1801. doi: 10.3389/fimmu.2019.01801

113. Komiya T, Huang $\mathrm{CH}$. Updates in the clinical development of epacadostat and other indoleamine 2,3-dioxygenase 1 inhibitors (IDO1) for human cancers. Front Oncol. (2018) 8:423. doi: 10.3389/fonc.2018. 00423

114. Svajger U, Obermajer N, Jeras M. IFN- $\gamma$-rich environment programs dendritic cells toward silencing of cytotoxic immune responses. J Leukoc Biol. (2014) 95:33-46. doi: 10.1189/jlb.1112589

115. Feuerer M, Eulenburg K, Loddenkemper C, Hamann A, Huehn J. Selflimitation of Th1-mediated inflammation by IFN-gamma. J Immunol. (2006) 176:2857-86. doi: 10.4049/jimmunol.176.5.2857

116. Lee CL, Guo Y, So KH, Vijayan M, Guo Y, Wong VHH, et al. Soluble human leukocyte antigen G5 polarizes differentiation of macrophages toward a decidual macrophage-like phenotype. Hum Reprod. (2015) 30:2263-74. doi: 10.1093/humrep/dev196

117. Leidi M, Gotti E, Bologna L, Miranda E, Rimoldi M, Sica A, et al. M2 macrophages phagocytose rituximab-opsonized leukemic targets more efficiently than M1 Cells In vitro. J Immunol. (2009) 182:4415-22. doi: 10.4049/jimmunol.0713732r

118. Tsai YC, Tseng JT, Wang CY, Su MT, Huang JY, Kuo PL. Medroxyprogesterone acetate drives M2 macrophage differentiation toward a phenotype of decidual macrophage. Mol Cell Endocrinol. (2017) 452:74-83. doi: 10.1016/j.mce.2017.05.015
119. Wheeler KC, Jena MK, Pradhan BS, Nayak N, Das S, Hsu CD, et al. VEGF may contribute to macrophage recruitment and M2 polarization in the decidua. PLoS ONE. (2018) 13:e0191040. doi: 10.1371/journal.pone.0191040

120. Guillemin GJ, Croitoru-Lamoury J, Dormont D, Armati PJ, Brew BJ. Quinolinic acid upregulates chemokine production and chemokine receptor expression in astrocytes. Glia. (2003) 41:371-81. doi: 10.1007/978-1-4615-0135-0_4

121. Fiala M, Zhang L, Gan XH, Sherry B, Taub D, Graves MC, et al. Amyloid-beta induces chemokine secretion and monocyte migration across a human blood-brain barrier model. Mol Med. (1998) 4:480-9. doi: 10.1007/BF03401753

122. Guillemin GJ, Smythe GA, Veas LA, Takikawa O, Brew BJ. A beta 1-42 induces production of quinolinic acid by human macrophages and microglia. Neuroreport. (2003) 14:2311-5. doi: 10.1097/00001756-200312190-00005

123. Guillemin GJ, Williams KR, Smith DG, Smythe GA, Croitoru-Lamoury J, Brew BJ. Quinolinic acid in the pathogenesis of Alzheimer's disease. Adv Exp Med Biol. (2003) 527:167.e176. doi: 10.1007/978-1-4615-0135-0_19

124. Ting KK, Brew B, Guillemin G. The involvement of astrocytes and kynurenine pathway in Alzheimer's disease. Neurotox Res. (2007) 12:247-62. doi: 10.1007/BF03033908

125. Widner B, Leblhuber F, Walli J, Tilz GP, Demel U, Fuchs D. Tryptophan degradation and immune activation in Alzheimer's disease. J Neural Transm. (2000) 107:343-53. doi: 10.1007/s007020050029

126. Wu W, Nicolazzo JA, Wen L, Chung R, Stankovic R, Bao SS, et al. Expression of tryptophan 2,3-dioxygenase and production of kynurenine pathway metabolites in triple transgenic mice and human Alzheimer's disease brain. PLoS ONE. (2013) 8:e59749. doi: 10.1371/journal.pone.0059749

127. Guillemin GJ, Wang L, Brew BJ. Quinolinic acid selectively induces apoptosis of human astrocytes: potential role in AIDS dementia complex. J Neuroinflammation. (2005) 2:16. doi: 10.1186/1742-2094-2-16

128. Rahman A, Ting K, Cullen KM, Braidy N, Brew BJ, Guillemin GJ. The excitotoxin quinolinic acid induces tau phosphorylation in human neurons. PLoS ONE. (2009) 4:e6344. doi: 10.1371/journal.pone.0006344

129. Bosco MC, Rapisarda A, Massazza S, Melillo G, Young H, Varesio L. The tryptophan catabolite picolinic acid selectively induces the chemokines macrophage inflammatory protein-1 alpha and-1 beta in macrophages. $J$ Immunol. (2000) 164:3283-91. doi: 10.4049/jimmunol.164.6.3283

130. Melillo G, Cox GW, Radzioch D, Varesio L. Picolinic-acid, a catabolite of 1tryptophan, a costimulus for the induction of reactive nitrogen intermediate production in murine macrophages. J Immunol. (1993) 150:4031-40.

131. Guillemin GJ, Cullen KM, Lim CK, Smythe GA, Garner B, Kapoor V, et al. Characterization of the kynurenine pathway in human neurons. J Neurosci. (2007) 27:12884-92.doi: 10.1523/JNEUROSCI.4101-07.2007

132. Jhamandas K, Boegman RJ, Beninger RJ, Bialik M. Quinolinate-induced cortical cholinergic damage - modulation by tryptophan-metabolites. Brain Res. (1990) 529:185-91. doi: 10.1016/0006-8993(90)90826-W

133. Vrooman L, Jhamandas K, Boegman RJ, Beninger RJ. Picolinic-acid modulates kainic acid-evoked glutamate release from the striatum in-vitro. Brain Res. (1993) 627:193-8. doi: 10.1016/0006-8993(93)90320-M

134. Beninger RJ, Colton AM, Ingles JL, Jhamandas K, Boegman, RJ. Picolinicacid blocks the neurotoxic but not the neuroexcitant properties of quinolinic acid in the rat-brain - evidence from turning behavior and tyrosine-hydroxylase immunohistochemistry. Neuroscience. (1994) 61:60312. doi: 10.1016/0306-4522(94)90438-3

135. Bryleva EY, Brundin L. Kynurenine pathway metabolites and suicidality. Neuropharmacology. (2017) 112:324-30. doi: 10.1016/j.neuropharm.2016.01.034

136. Mancuso R, Hernis A, Agostini S, Rovaris M, Caputo D, Fuchs D, et al. Indoleamine 2,3 dioxygenase (IDO) expression and activity in relapsing-remitting multiple sclerosis. PLOS ONE. (2015) 10:e0130715. doi: 10.1371/journal.pone.0130715

137. Lim CK, Brew BJ, Sundaram G, Guillemin GJ. Understanding the roles of the kynurenine pathway in multiple sclerosis progression. Int J Tryptophan Res. (2010) 3:157-67. doi: 10.4137/IJTR.S4294

138. Platten M, Ho PP, Youssef S, Fontoura P, Garren H, Hur EM, et al. Treatment of autoimmune neuroinflammation with a synthetic tryptophan metabolite. Science. (2005) 310:850-5. doi: 10.1126/science.1117634 
139. Hartai Z, Klivenyi P, Janaky T, Penke B, Dux L, Vecsei L. Kynurenine metabolism in multiple sclerosis. Acta Neurol Scand. (2005) 112:93-6. doi: 10.1111/j.1600-0404.2005.00442.x

140. Chiarugi A, Cozzi A, Ballerini C, Massacesi L, Moroni F. Kynurenine 3mono-oxygenase activity and neurotoxic kynurenine metabolites increase in the spinal cord of rats with experimental allergic encephalomyelitis. Neuroscience. (2001) 102:687-95. doi: 10.1016/S0306-4522(00)00504-2

141. Sakurai K, Zou JP, Tschetter JR, Ward JM, Shearer GM. Effect of indoleamine 2,3-dioxygenase on induction of experimental autoimmune encephalomyelitis. J Neuroimmunol. (2002) 129:186-96. doi: 10.1016/S0165-5728(02)00176-5

142. Kwidzinski E, Bunse J, Aktas O, Richter D, Mutlu L, Zipp F, et al. Indolamine 2,3-dioxygenase is expressed in the CNS and down-regulates autoimmune inflammation. FASEB J. (2005) 19:1347-9. doi: 10.1096/fj.04-3228fje

143. Kwidzinski E, Bechmann I. IDO expression in the brain: a double-edged sword. J Mol Med. (2007) 85:1351-9. doi: 10.1007/s00109-007-0229-7

144. Savitz J, Dantzer R, Meier TB, Wurfel BE, Victor TA, McIntosh SA, et al. Activation of the kynurenine pathway is associated with striatal volume in major depressive disorder. Psychoneuroendocrinology. (2015) 62:54-8. doi: 10.1016/j.psyneuen.2015.07.609

145. Stone TW, Darlington LG. The kynurenine pathway as a therapeutic target in cognitive and neurodegenerative disorders. Br J Pharmacol. (2013) 169:1211-27. doi: 10.1111/bph.12230s

146. Erhardt S, Schwieler L, Imbeault S, Engberg G. The kynurenine pathway in schizophrenia and bipolar disorder. Neuropharmacology. (2017) 112:297306. doi: 10.1016/j.neuropharm.2016.05.020

147. Wonodi I, Stine OC, Sathyasaikumar KV, Robers RC, Mitchell BD, Hong LE, et al. Downregulated kynurenine 3-monooxygenase gene expression and enzyme activity in schizophrenia and genetic association with schizophrenia endophenotypes. Arch Gen Psychiatry. (2011) 68:665-74. doi: 10.1001/archgenpsychiatry.2011.71.

148. Owe-Young R, Webster NL, Mukhtar M, Pomerantz RJ, Smythe G, Walker $\mathrm{D}$, et al. Kynurenine pathway metabolism in human blood-brain-barrier cells: implications for immune tolerance and neurotoxicity. J Neurochem. (2008) 105:1346-57. doi: 10.1111/j.1471-4159.2008.05241.x

149. Steiner J, Bogerts B, Sarnyai Z, Walter M, Gos T, Bernstein HG, et al. Bridging the gap between the immune and glutamate hypotheses of schizophrenia and major depression: potential role of glial NMDA receptor modulators and impaired blood-brain barrier integrity. World J Biol Chem. (2012) 13:482-92. doi: $10.3109 / 15622975.2011 .583941$

150. Guillemin GJ. Quinolinic acid, the inescapable neurotoxin. FEBS J. (2012) 79:1356-65. doi: 10.1111/j.1742-4658.2012.08485.x

151. St’astný F, Skultétyová I, Pliss L, Jezová D. Quinolinic acid enhances permeability of rat brain microvessels to plasma albumin. Brain Res Bull. (2000) 53:415-20. doi: 10.1016/S0361-9230(00)00368-3

152. Baranyi A, Amouzadeh-Ghadikolai O, vone Lewinski D, Breitenecker RJ, Stojakovic T, Maerz W, et al. Beta-trace protein as a new noninvasive immunological marker for quinolinic acid-induced blood-brain barrier integrity. Sci Rep. (2017) 7:43642. doi: 10.1038/srep43642

153. Olah G, Heredi J, Menyhart A, Czinege Z, Nagy D, Fuzik J, et al. Unexpected effects of peripherally administered kynurenic acid on cortical spreading depression and related blood-brain barrier permeability. Drug Des Dev Ther. (2013) 7:981-7. doi: 10.2147/DDDT.S44496

154. Maes M, Yirmiya R, Noraberg J, Brene S, Hibbeln J, Perini G, et al. The inflammatory and neurodegenerative hypothesis of depression: leads for future research and new drug developments in depression. Metab Brain Dis. (2009) 24:27-53. doi: 10.1007/s11011-008-9118-1

155. Dantzer R, O’Connor JC, Lawson MA, Kelley KW. (2011). Inflammation-associated depression: from serotonin to kynurenine. Psychoneuroendocrinology. 36:426-436. doi: 10.1016/j.psyneuen.2010. 09.012

156. Reus GZ, Jansen K, Titus S, Carvalho AF, Gabbay V, Quevedo J. Kynurenine pathway dysfunction in the pathophysiology and treatment of depression: evidences from animal and human studies. J Psychiat Res. (2015) 68:316-28. doi: 10.1016/j.jpsychires.2015.05.007

157. Sforzini L, Nettis MA, Mondelli V, Pariante CM. Inflammation in cancer and depression: a starring role for the kynurenine pathway. Psychopharmacology. (2019) 236:2997-3011. doi: 10.1007/s00213-019-05200-8
158. Stone TW. Does kynurenic acid act on nicotinic receptors? An assessment of the evidence. J. Neurochem. (in press). doi: 10.1111/jnc.14907

159. Miller AH, Haroon E, Raison CL, Felger JC. Cytokine targets in the brain: impact on neurotransmitters and neurocircuits. Depress Anxiety. (2013) 30:297-306. doi: 10.1002/da.22084

160. Clark CJ, Mackay GM, Smythe GA, Bustamante S, Stone TW, Phillips RS. Prolonged survival of a murine model of cerebral malaria by kynurenine pathway inhibition. Infect Immun. (2005) 73:5249-51. doi: 10.1128/IAI.73.8.5249-5251.2005

161. Forrest CM, Khalil OS, Pisar M, Darlington LG, Stone TW. Prenatal inhibition of the tryptophan - kynurenine pathway alters synaptic plasticity and protein expression in the rat hippocampus. Brain Res. (2013) 1504:1-15. doi: 10.1016/j.brainres.2013.01.031

162. Forrest CM, Khalil OS, Pisar M, McNair K, Kornisiuk E, Snitcofsky M, et al. Changes in synaptic transmission and protein expression in the brains of adult offspring after prenatal inhibition of the kynurenine pathway. Neuroscience. (2013) 254:241-59. doi: 10.1016/j.neuroscience.2013.09.034

163. Khalil OS, Pisar M, Forrest CM, Vincenten MCJ, Darlington LG, Stone TW. Prenatal inhibition of the kynurenine pathway leads to structural changes in the hippocampus of adult rat offspring. Euro J Neurosci. (2014) 39:1558-71. doi: 10.1111/ejn.12535

164. Pisar M, Forrest CM, Khalil OS, McNair K, Vincenten MCJ, Qasem S, et al. Modified neocortical and cerebellar protein expression and morphology following prenatal inhibition of the kynurenine pathway. Brain Res. (2014) 1576:1-17. doi: 10.1016/j.brainres.2014.06.016

165. Forrest CM, McNair K, Pisar M, Khalil OS, Darlington LG, Stone TW. Altered hippocampal plasticity by prenatal kynurenine administration, kynurenine-3-monoxygenase (KMO) deletion or galantamine. Neuroscience. (2015) 310:91-105. doi: 10.1016/j.neuroscience.2015.09.022

166. Giorgini F, Huang SY, Sathyasaikumar KV, Notarangelo FM, Thomas MAR, Tararina M, et al. Targeted deletion of kynurenine 3-monooxygenase in mice: a new tool for studying kynurenine pathway metabolism in periphery and brain. J Biol Chem. (2013) 288:36554-66. doi: 10.1074/jbc.M113.503813

167. Rodgers J, Stone TW, Barrett MP, Bradley B, Kennedy PGE. Kynurenine pathway inhibition reduces central nervous system inflammation in a model of human African trypanosomiasis. Brain. (2009) 132:1259-67. doi: 10.1093/brain/awp074

168. Milosavljevic N, Gazdic M, Markovic BS, Arsenijevic A, Nurkovic J, Dolicanin Z, et al. Mesenchymal stem cells attenuate liver fibrosis by suppressing Th17 cells - an experimental study. Transpl Int. (2018) 31:10215. doi: $10.1111 /$ tri.13023

169. Markovic BS, Gazdic M, Arsenijevic A, Jovicic N, Jeremic J, Djonov V, et al. Mesenchymal stem cells attenuate cisplatin-induced nephrotoxicity in iNOS-dependent manner. Stem Cells Int. (2017) 2017:1315378. doi: $10.1155 / 2017 / 1315378$

170. Gazdic M, Markovic BS, Jovicic N, Misirkic-Marjanovic M, Djonov V, Jakovljevic V, et al. Mesenchymal stem cells promote metastasis of lung cancer cells by downregulating systemic antitumor immune response. Stem Cells Int. (2017) 2017:6294717. doi: 10.1155/2017/6294717

171. Mariuzzi L, Domenis R, Orsaria M, Marzinotto S, Londero AP, Bulfoni $\mathrm{M}$, et al. Functional expression of aryl hydrocarbon receptor on mast cells populating human endometriotic tissues. Lab Invest. (2016) 96:959-71. doi: 10.1038/labinvest.2016.74

172. Deac OM, Mills JL, Gardiner CM, Shane B, Quinn L, Midttun O, et al. Serum immune system biomarkers neopterin and interleukin-10 are strongly related to tryptophan metabolism in healthy young adults. J Nutr. (2016) 146:1801-6. doi: 10.3945/jn.116.230698

173. Wirthgen E, Otten W, Tuchscherer M, Tuchscherer A, Domanska G, Brenmoehl J, et al. Effects of 1-methyltryptophan on immune responses and the kynurenine pathway after lipopolysaccharide challenge in pigs. Int J Mol Sci. (2018) 19:3009. doi: 10.3390/ijms19103009

174. Farup PG, Ueland T, Rudi K, Lydersen S, Hestad K. Functional bowel disorders are associated with a central immune activation. Gastroenterol Res Pract. (2017) 2017:1642912. doi: 10.1155/2017/1642912

175. Pichler R, Gruenbacher G, Culig Z, Brunner A, Fuchs D, Fritz J, et al. Intratumoral Th2 predisposition combines with an increased Th1 functional phenotype in clinical response to intravesical BCG in bladder cancer. Cancer Immunol Immunother. (2017) 66:427-40. doi: 10.1007/s00262-016-1945-Z 
176. Coutinho LG, Christen S, Bellac CL, Fontes FL, Soares de Souza FR, Grandgirard D, et al. The kynurenine pathway is involved in bacterial meningitis. J Neuroinflamm. (2014) 11:169.doi: 10.1186/s12974-014-0169-4

177. Metghalchi S, Ponnuswamy P, Simon T, Haddad Y, Laurans L, Clement $\mathrm{M}$, et al. Indoleamine 2,3-dioxygenase fine-tunes immune homeostasis in atherosclerosis and colitis through repression of interleukin-10 production. Cell Metab. (2015) 22:460-71. doi: 10.1016/j.cmet.2015.07.004

178. Maneechotesuwan K, Kasetsinsombat K, Wamanuttajinda V, Wongkajornsilp A, Barnes PJ. Statins enhance the effects of corticosteroids on the balance between regulatory T cells and Th17 cells. Clin Exp Allergy. (2013) 43:212-22. doi: 10.1111/cea.12067

179. de Araujo EF, Feriotti C, de Lima Galdino NA, Preite NW, Garcia CVL, Loures FV. The IDO-AHR axis controls Th17/treg immunity in a pulmonary model of fungal infection. Front Immunol. (2017) 8:880. doi: 10.3389/fimmu.2017.00880

180. Zheng S, Shao S, Qiao Z, Chen X, Piao C, Yu Y, et al. Clinical parameters and gut microbiome changes before and after surgery in thoracic aortic dissection in patients with gastrointestinal complications. Sci Rep. (2017) 7:15228. doi: 10.1038/s41598-017-15079-0

181. Matysik-Wozniak A, Paduch R, Turski WA, Maciejewski R, Juenemann AG, Rejdak R. Effects of tryptophan, kynurenine and kynurenic acid exerted on human reconstructed corneal epithelium in vitro. Pharmacol Rep. (2017) 69:722-9. doi: 10.1016/j.pharep.2017.02.020

182. Wiedlocha M, Marcinowicz P, Krupa R, Janoska-Jazdzik M, Janus M, Debowska W, et al. Effect of antidepressant treatment on peripheral inflammation markers - a meta-analysis. Progr Neuropsychopharmacol Biol Psychiatry. (2018) 80:217-26. doi: 10.1016/j.pnpbp.2017.04.026

183. Rao NP, Venkatasubramanian G, Ravi V, Kalmady S, Cherian A, Reddy J. Plasma cytokine abnormalities in drug-naive, comorbidityfree obsessive-compulsive disorder. Psychiatry Res. (2015) 229:949-52. doi: 10.1016/j.psychres.2015.07.009

184. Yang RN, Gao N, Chang Q, Meng XC, Wang WH. The role of IDO, IL-10 and TGF- $\beta$ in the HCV-associated chronic hepatitis, liver cirrhosis and hepatocellular carcinoma. J Med Virol. (2019) 91:265-71. doi: 10.1002/jmv.25083

185. Lanis JM, Alexeev EE, Curtis VF, Kitzenberg DA, Kao DJ, Battista KD, et al. Tryptophan metabolite activation of the aryl hydrocarbon receptor regulates IL-10 receptor expression on intestinal epithelia. Mucosal Immunol. (2017) 10:1133-44. doi: 10.1038/mi.2016.133

186. Kim NS, Torrez T, Langridge W. LPS enhances CTB-insulin induction of IDO1 and IL-10 synthesis in human dendritic cells. Cell Immunol. (2019) 338:32-42. doi: 10.1016/j.cellimm.2019.03.003

187. Coquerelle C, Oldenhove G, Acolty V, Denoeud J, Vansanten G, Verdebout JM, et al. Anti-CTLA-4 treatment induces IL-10-producing ICOS + regulatory $\mathrm{T}$ cells displaying IDO-dependent anti-inflammatory properties in a mouse model of colitis. Gut. (2009) 58:1363-73. doi: 10.1136/gut.2008.162842

188. Luo CF, Jia WW, Wang K, Chi FL, Gu YQ, Yan XL, et al. Human amniotic fluid stem cells suppress PBMC proliferation through IDO and IL-10-dependent pathways. Curr Stem Cell Res Ther. (2014) 9:36-45. doi: 10.2174/1574888X113086660067

189. Alameddine J, Godefroy E, Papargyris L, Sarrabayrouse G, Tabiasco J, Bridonneau C, et al. Faecalibacterium prausnitzii skews human DC to prime IL10-producing T cells through TLR2/6/JNK signalling and IL10, IL-27, CD39 and IDO-1 induction. Front Immunol. (2019) 10:143. doi: $10.3389 /$ fimmu.2019.00143

190. Eisenbacher JL, Schrezenmeier H, Jahrsdorfer B, Kaltenmeier C, Rojewski MT, Yildiz T, et al. S100A4 and uric acid promote mesenchymal stromal cell induction of IL-10(+)/IDO+ lymphocytes. J Immunol. (2014) 192:6102-10. doi: 10.4049/jimmunol.1303144

191. Banerjee T, DuHadaway JB, Gaspari P, Sutanto-Ward E, Munn DH, Mellor $\mathrm{AL}$, et al. A key in vivo antitumor mechanism of action of natural productbased brassinins is inhibition of indoleamine-2,3-dioxygenase. Oncogene. (2008) 27:2851-7. doi: 10.1038/sj.onc.1210939

192. Miller CA. Expression of the human aryl hydrocarbon receptor complex in yeast. Activation of transcription by indole compounds. J Biol Chem. (1997) 272:32824-9. doi: 10.1074/jbc.272.52. 32824
193. Guengerich PF, Martin MV, McCormick WA, Nguyen LP, Glover E, Bradfield CA. Aryl hydrocarbon receptor response to indigoids in vitro and in vivo. Arch Biochem Biophys. (2004) 423:309-16. doi: 10.1016/j.abb.2004.01.002

194. Benson JM, Shepherd DM. Aryl hydrocarbon receptor activation by tcdd reduces inflammation associated with Crohn's Disease. Toxicol Sci. (2011) 120:68-78. doi: 10.1093/toxsci/kfq360

195. Benson JM, Shepherd DM. Dietary ligands of the aryl hydrocarbon receptor induce anti-inflammatory and immunoregulatory effects on murine dendritic cells. Toxicol Sci. (2011) 124:327-38. doi: 10.1093/toxsci/kfr249

196. Notarangelo FM, Pocivaysek A. Elevated kynurenine pathway metabolism during neurodevelopment: Implications for brain and behaviour. Neuropharmacology. (2017) 112:275-85. doi: 10.1016/j.neuropharm.2016.03.001

197. Pocivavsek A, Thomas MAR, Elmer GI, Bruno JP, Schwarcz R. Continuous kynurenine administration during the prenatal period, but not during adolescence, causes learning and memory deficits in adult rats. Psychopharmacology. (2014) 231:2799-809. doi: 10.1007/s00213-014-3452-2

198. Pocivavsek A, Elmer GI, Schwarcz R. Inhibition of kynurenine aminotransferase II attenuates hippocampus-dependent memory deficit in adult rats treated prenatally with kynurenine. Hippocampus. (2019) 29:73-7. doi: 10.1002/hipo. 23040

199. Hahn B, Reneski CH, Pocivavsek A, Schwarcz R. Prenatal kynurenine treatment in rats causes schizophrenia-like broad monitoring deficits in adulthood. Psychopharmacology. (2018) 235:651-61.doi: 10.1007/s00213-017-4780-9

200. Schwieler L, Larsson MK, Skogh E, Kegel ME, Orhan F, Abdelmoaty S, et al. Increased levels of IL-6 in the cerebrospinal fluid of patients with chronic schizophrenia - significance for activation of the kynurenine pathway. $J$ Psychiat Neurosci. (2015) 40:126-33. doi: 10.1503/jpn.140126

201. Anderson G, Maes M. Schizophrenia: linking prenatal infection to cytokines, the tryptophan catabolite (TRYCAT) pathway, NMDA receptor hypofunction, neuro-development and neuroprogression. Progr Neuropsychopharmacol Biol Psychiatry. (2013) 42:5-19. doi: 10.1016/j.pnpbp.2012.06.014

202. Vorhees CV, Graham DL, Braun AA, Schaefer TL, Skelton MR, Richtand NM, et al. Prenatal immune challenge in rats: Effects of polyinosinicpolycytidylic acid on spatial learning, prepulse inhibition, conditioned fear, and responses to MK-801 and amphetamine. Neurotoxicol Teratol. (2015) 47:54-65. doi: 10.1016/j.ntt.2014.10.007

203. Meehan C, Harms L, Frost JD, Barreto R, Todd J, Schall U, et al. Effects of immune activation during early or late gestation on schizophreniarelated behaviour in adult rat offspring. Brain Behav Immun. (2017) 63:8-20. doi: 10.1016/j.bbi.2016.07.144

204. Mueller N. Inflammation in schizophrenia: pathogenetic aspects and therapeutic considerations. Schizophrenia Bull. (2018) 44:973-82. doi: 10.1093/schbul/sby024

205. Clark SM, Notarangelo FM, Li X, Chen S, Schwarcz R, Tonelli LH. Maternal immune activation in rats blunts brain cytokine and kynurenine pathway responses to a second immune challenge in early adulthood. Prog Neuropsychopharmacol Biol Psychiatry. (2019) 89:286-94. doi: 10.1016/j.pnpbp.2018.09.011

206. Zager A, Pinheiro ML, Ferraz-de-Paula V, Ribeiro A, Palermo-Neto J. Increased cell-mediated immunity in male mice offspring exposed to maternal immune activation during late gestation. Int Immunopharmcol. (2013) 17:633-637. doi: 10.1016/j.intimp.2013.08.007

207. Song W, Zsindely N, Farago A, Marsh JL, Bodai L. Systematic genetic interaction studies identify histone demethylase UTX as potential target for ameliorating Huntington's disease. Hum Mol Genet. (2018) 27:649-66. doi: $10.1093 / \mathrm{hmg} / \mathrm{ddx} 432$

208. Thomas EA. DNA methylation in Huntington's disease: implications for trans-generational effects. Neurosci Lett. (2016) 625:34-9. doi: 10.1016/j.neulet.2015.10.060

209. Yeh HH, Young D, Gelovani JG, Robinson A, Davidson Y, Herholz K, et al. Histone deacetylase class II and acetylated core histone immunehistochemistry in human brains with Huntington's disease. Brain Res. (2013) 1504:16-24. doi: 10.1016/j.brainres.2013.02.012

210. Suelves N, Kirkham-McCarthy L, Lahue RS, Gines S. A selective inhibitor of histone deacetylase 3 prevents cognitive deficits and suppresses striatal 
CAG repeat expansions in Huntington's disease mice. Sci Rep. (2017) 7:6082. doi: 10.1038/s41598-017-05125-2

211. Mollica PA, Reid JA, Ogle RC, Sachs PC, Bruno RD. DNA Methylation leads to DNA repair gene down-regulation and trinucleotide repeat expansion in patient-derived Huntington disease cells. Am J Pathol. (2016) 186:1967-76. doi: 10.1016/j.ajpath.2016.03.014

212. Angiolilli C, Kabala PA, Grabiec AM, Van Baarsen IM, Ferguson BS, Garcia $\mathrm{S}$, et al. Histone deacetylase 3 regulates the inflammatory gene expression programme of rheumatoid arthritis fibroblast-like synoviocytes. Ann Rheum Dis. (2017) 76:277-85. doi: 10.1136/annrheumdis-2015-209064

213. Oh BR, Suh DH, Bae D, Ha N, Choi Y, Yoo HJ, et al. Therapeutic effect of a novel histone deacetylase 6 inhibitor, CKD-L, on collagen-induced arthritis in vivo and regulatory $\mathrm{T}$ cells in rheumatoid arthritis in vitro. Arthritis Res Ther. (2017) 19:154. doi: 10.1186/s13075-017-1357-2

214. Ai R, Hammaker D, Boyle DL, Morgan R, Walsh AM, Fan S, et al. Jointspecific DNA methylation and transcriptome signatures in rheumatoid arthritis identify distinct pathogenic processes. Nat Comm. (2016) 7:11849. doi: $10.1038 /$ ncomms11849

215. Lin Y, Luo Z. Aberrant methylation patterns affect the molecular pathogenesis of rheumatoid arthritis. Int Immunopharmacol. (2017) 46:1415. doi: 10.1016/j.intimp.2017.02.008

216. Glossop JR, Nixon NB, Emes RD, Sim J, Packham JC, Mattey DL, et al. DNA methylation at diagnosis is associated with response to diseasemodifying drugs in early rheumatoid arthritis. Epigenomics. (2017) 9:419-28. doi: 10.2217/epi-2016-0042

217. Fang G, Zhang QH, Tang Q, Jiang Z, Xing S, Li J, et al. Comprehensive analysis of gene expression and DNA methylation datasets identify valuable biomarkers for rheumatoid arthritis progression. Oncotarget. (2018) 9:297783. doi: $10.18632 /$ oncotarget.22918

218. Zafari P, Yari K, Mostafaei S, Iranshahi N, Assar S, Fekri A, et al. Analysis of Helios gene expression and Foxp3 TSDR methylation in the newly diagnosed rheumatoid arthritis patients. Immunol Invest. (2018) 47:632-42. doi: 10.1080/08820139.2018.1480029

219. Araki Y, Aizaki Y, Sato K, Oda H, Kurokawa R, Mimura T. Altered gene expression profiles of histone lysine methyltransferases and demethylases in rheumatoid arthritis synovial fibroblasts. Clin Exp Rheumatol. (2018) 36:314-6.

220. Plant D, Webster A, Nair N, Oliver J, Smith SL, Eyre S, et al. Differential methylation as a biomarker of response to etanercept in patients with rheumatoid arthritis. Arthritis Rheumatol. (2016) 68:1353-60. doi: 10.1002/art.39590

221. Jacobs KR, Castellano-Gonzalez G, Guillemin GJ, Lovejoy DB. Major developments in the design of inhibitors along the kynurenine pathway. Curr Med Chem. (2017) 24:2471-95. doi: 10.2174/0929867324666170502123114

222. Dounay AB, Tuttle JB, Verhoestt PR. Challenges and opportunities in the discovery of new therapeutics targeting the kynurenine pathway. J Med Chem. (2015) 26:8762-82. doi: 10.1021/acs.jmedchem.5b00461

223. Phillips RS, Iradukunda EC, Hughes T, Bowen JP. Modulation of Enzyme Activity in the Kynurenine Pathway by Kynurenine Monooxygenase Inhibition. Front Molec Biosci. (2019) 6:3. doi: 10.3389/fmolb.2019.00003

224. Hutchinson JP, Rowland P, Taylor MRD, Christodoulou EM, Haslam C, Hobbs CI, et al. Structural and mechanistic basis of differentiated inhibitors of the acute pancreatitis target kynurenine-3-monooxygenase. Nature Commun. (2017) 8:15827. doi: 10.1038/ncomms15827

225. Walker AL, Ancellin N, Beaufils B, Bergeal M, Binnie M, Bouillot A et al. Development of a series of kynurenine 3-monooxygenase inhibitors leading to a clinical candidate for the treatment of acute pancreatitis. J Med Chem. (2017) 60:3383-04. doi: 10.1021/acs.jmedchem.7b00055
226. Amin SA, Adhikari N, Jha, T, Gayen S. First molecular modeling report on novel arylpyrimidine kynurenine monooxygenase inhibitors through multiQSAR analysis against Huntington's disease: A proposal to chemists! Bioorg Med Chem Lett. (2016) 26:5712-18. doi: 10.1016/j.bmcl.2016.10.058

227. Rossi F, Miggiano R, Ferraris DM, Rizzi M. The synthesis of kynurenic acid in mammals: an updated kynurenine aminotransferase structural katalogue. Front Molec Biosci. (2019) 6:7. doi: 10.3389/fmolb.2019.00007

228. Nematollahi A, Sun GC, Jayawickrama GS, Hanrahan JR, Church WB. Study of the activity and possible mechanism of action of a reversible inhibitor of recombinant human KAT-2: a promising lead in neurodegenerative and cognitive disorders. Molecules. (2016) 21:856. doi: 10.3390/molecules 21070856

229. Pellicciari R, Liscio P, Giacche N, De Franco F, Carotti A, Robertson J. et al. Alpha-Amino-beta-carboxymuconate-epsilon-semialdehyde Decarboxylase (ACMSD) inhibitors as novel modulators of de novo nicotinamide adenine dinucleotide (NAD $(+)$ ) biosynthesis. J Med Chem. (2018) 61:745-59. doi: 10.1021/acs.jmedchem.7b01254

230. Yoshida Y, Fujigaki H, Kato K, Yamazaki K, Fujigaki S, Kunisawa K, et al. Selective and competitive inhibition of kynurenine aminotransferase 2 by glycyrrhizic acid and its analogues. Sci Rept. (2019) 9:10243. doi: 10.1038/s41598-019-46666-y

231. Hu H, Li M, Wu D, Li ZW, Miao RF, Liu Y, et al. Design, synthesis and biological evaluation of novel aryl-acrylic derivatives as novel indoleamine2,3-dioxygenase 1 (IDO1) inhibitors. Bioorg Med Chem. (2019) 27:3135-44. doi: 10.1016/j.bmc.2019.05.048

232. Yang R, Chen Y, Pan LK, Yang YY, Zheng Q, Hu Y, et al. Design, synthesis and structure-activity relationship study of novel naphthoindolizine and indolizinoquinoline-5,12-dione derivatives as IDO1 inhibitors. Bioorg Med Chem. (2018) 26:4886-97. doi: 10.1016/j.bmc.2018.08.028

233. Pan LK, Zheng Q, Chen Y, Yang R, Yang YY, Li ZJ, et al. Design, synthesis and biological evaluation of novel naphthoquinone derivatives as IDO1 inhibitors. Europ J Med Chem. (2018) 157:423-36. doi: 10.1016/j.ejmech.2018.08.013

234. Zou Y, Wang F, Wang Y, Sun QR, Hu Y, Li YZ, et al. Discovery of imidazoleisoindole derivatives as potent IDO1 inhibitors: Design, synthesis, biological evaluation and computational studies. Europ J Med Chem. (2017) 140:293-304. doi: 10.1016/j.ejmech.2017. 09.025

235. Gao DD, Li YX. Identification and preliminary structure-activity relationships of 1-Indanone derivatives as novel indoleamine-2,3dioxygenase 1 (IDO1) inhibitors. Bioorg Med Chem. (2017) 25:3780-91. doi: 10.1016/j.bmc.2017.05.017

236. Schwarcz R, Stone TW. The kynurenine pathway and the brain: challenges, controversies and promises. Neuropharmacology. (2017) 112:237-47. doi: 10.1016/j.neuropharm.2016. 08.003

Conflict of Interest: The authors declare that the research was conducted in the absence of any commercial or financial relationships that could be construed as a potential conflict of interest.

Copyright $\odot 2020$ Huang, Ogbechi, Clanchy, Williams and Stone. This is an openaccess article distributed under the terms of the Creative Commons Attribution License (CC BY). The use, distribution or reproduction in other forums is permitted, provided the original author(s) and the copyright owner(s) are credited and that the original publication in this journal is cited, in accordance with accepted academic practice. No use, distribution or reproduction is permitted which does not comply with these terms. 